NBER WORKING PAPER SERIES

\title{
MONETARY POLICY WTTH FLEXIBLE \\ EXCHANGE RATES AND FORWARD \\ INTEREST RATES AS INDICATORS
}

Lars E. O. Svensson

Working Paper No. 4633

\section{NATIONAL BUREAU OF ECONOMIC RESEARCH \\ 1050 Massachusetts Avenue \\ Cambridge, MA 02138 \\ January 1994}

Presented at the 13th Bank of France-University Conference, "Capital Movements and Exchange Rate Politics," November 24-26, 1993, and to be published in Cahiers Economiques et Monétaires. I thank the discussant Jean-Pierre Laffargue and conference participants for comments. I also thank Roel Beetsma, Magnus Dahlquist, Jon Faust, Mark Fisher, Lars Hörngren, Assar Lindbeck, Hans Lindberg, Maurice Obstfeld, Vincent Reinhart, Anders Vredin, David Zervos, and participants in a seminar at the Stockholm School of Economics for discussions and comments on a previous version; Mårten Blix and Joakim Persson for research assistance; and Molly Ákerlund and Patricia Reinhold for secretarial and editorial assistance. This paper is part of NBER's research programs in International Finance and Macroeconomics and Monetary Economics. Any opinions expressed are those of the author and not those of the National Bureau of Economic Research. 
NBER Working Paper \#4633

January 1994

\title{
MONETARY POLICY WITH FLEXIBLE \\ EXCHANGE RATES AND FORWARD \\ INTEREST RATES AS INDICATORS
}

\begin{abstract}
In the new situation with flexible exchange rates, monetary policy in Europe will have to rely more on indicators than previously under fixed rates. One of the potential indicators, the forward interest rate curve, can be used to indicate market expectations of the time-paths of future short interest rates, monetary policy, inflation rates and currency depreciation rates. The forward rate curve separates market expectations for the short, medium and long tern more easily than the standard yield curve. Monetary policy in France, Germany, Great Britain, Sweden and the United States is interpreted with the help of forward rates.
\end{abstract}

Lars E. O. Svensson

Institute for Intemational Economic Studies

Stockholm University

10691 Stockholm

SWEDEN

CEPR and NBER 


\section{Introduction}

Previous monetary policy with fixed exchange rates in Europe the last few years can be described, with some simplification, as Germany's pursuing an independent monetary policy directed as domestic price stability, and the rest of the countries' pegging their exchange rate to the German mark, the European anchor currency. This was the case for the countries within the ERM as well as the countries outside the ERM that unilaterally pegged their exchange rate to the mark, as Austria, or the ecu, as Finland, Norway and Sweden. Monetary policy outside Germany was then in principle very simple, it consisted solely in defending a fixed exchange rate towards the mark or the ecu. This in turn, again with some simplification, implied that central banks had to set interest rates so as to roughly balance capital flows.

The last year's turmoil in Europe has dramatically changed this. The Finnish markka, the Italian lira and the British pound were forced to float in September 1992. In November the same year the Swedish krona was floated, in December the Norwegian krone. In August 1993 the exchange rate bands for the currencies that remained in the ERM were increased to \pm 15 percent, with the exception of the German mark and the Dutch guilder which remained in the narrow band.

The loss of the fixed exchange rates means the loss of the nominal anchor for the countries that used to peg their exchange rates to the mark or the ecu. Except for Austria and the Netherlands, fixed exchange rates do not now seem a realistic alternative for the European countries in the short or medium term. Even if fixed exchange rates towards a stable currency were feasible, if the ultimate target for monetary policy is price stability, one can seriously doubt the efficiency of fixed exchange rates as an intermediate target to achieve price stability (see Svensson (1994)). Hence, for several reasons there is a need to discuss how monetary policy should be designed in the new situation with flexible exchange rates in Europe.

This paper briefly discusses the design of monetary policy with flexible exchange rates, in terms of the convenient and generally accepted conceptual framework of goals, intermediate targets, indicators and instruments of monetary policy. It argues that likely difficulties in finding appropriate intermediate targets will increase the role of indicators for assessing the state of the economy, the stance of monetary policy, and how the instruments should be adjusted to achieve the goal of monetary policy. Several indicators will have to be used simultaneously. The paper extends on the use of one of the possible indicators, the forward interest rate, and discusses how forward interest rates can be 
used to extract market expectations of future interest rate, inflation rates and currency depreciation rates. Some discussion and interpretation of forward interest rates in France, Germany, Great Britain, Sweden and the United States is provided. ${ }^{1}$

The paper is outlined as follows. Section 2 discusses the design of monetary policy with flexible exchange rates in terms of the conceptual framework of goals, intermediate targets, indicators and instruments. Section 3 provides definitions of yields to maturity, zero-coupon interest rates (spot rates) and forward interest rates. Sections 4, 5 and 6 discusses how forward interest rates can be used to extract expected future interest rates, expected future inflation, and expected future currency depreciation, respectively. Three different risk premia (term, inflation, and foreign exchange risk premia) are defined and discussed. Section 7 provides a comparison and discussion of forward interest rates in France, Germany, Great Britain, Sweden and the United States. Section 8 concludes. Appendix A reports on the estimation of forward rates from bond yields, and Appendix $B$ defines three related concepts of term premia.

\section{Monetary Policy with Flexible Exchange Rates}

A generally accepted conceptual framework for the design of monetary policy distinguishes between goals, intermediate targets, indicators and instruments (see Friedman (1990) or McCallum (1990), for example). ${ }^{2}$ As the term implies, the goals of monetary policy-price stability and full employment, for example-are the ultimate objectives of monetary policy. Monetary policy is complicated by the fact that the central bank has only very indirect control over the variables that usually constitute the goals. These variables react with long and variable lags to monetary policy. The variables thernselves are observed with sometimes rather substantial delays, at rather long intervals, and with substantial statistical uncertainty. Some central banks select intermediate targets such as various money-supply aggregates or the exchange rate. These intermediate targets do not necessarily have any intrinsic value, apart from their correlation with the goals. They are more controllable and more readily observed than the goals (they are observed more often, with less time lag, and react more quickly to monetary policy). Properly chosen intermediate targets can therefore contribute to fulfilling the goals. Indicators are variables that provide the

\footnotetext{
'Forward interest rates are already used as one of the monetary policy indicators by Bank of England, Board of Governors of the Federal Reserve System, and Sveriges Riksbank. Their role as indicators is discussed in Bank of England (1993b), Svensson (1993a) and Sveriges Riksbank (1993). See also Bank for International Settlements (1993, p. 144).

${ }^{2}$ This section builds to some extent upon Svensson (1992).
} 
central bank with information on the state of the economy (inflation pressure and inflation expectations, for example) or on the monetary policy stance (that is, how expansive the monetary policy is). Indicators thus offer the central bank guidance on how monetary policy should be conducted in order to achieve the goals. Depending on the design of the monetary policy, a variable may be an indicator or intermediate target. To illustrate, the exchange rate is an intermediate target when fixed, but an indicator when flexible. As a rule, the indicator function of a variable ceases if the variable becomes an intermediate target. Short and long interest rates, credit volume, employment and wage settlements are other examples of indicators. Finally, instruments - such as the interest rate at which the central bank lends reserves to private banks, or the monetary base or some component thereof - are variables that are subject to direct daily control of the central bank and which the bank can employ to implement monetary policy. The instruments chosen and the rules by which the instruments are adjusted define the day-to-day implementation of monetary policy. Most central banks employ a short-term interest rate as their instrument. Some empirical evidence and practical experience indicate that the choice of instruments is not so important. ${ }^{3}$

The design of monetary policy involves selecting goals, intermediate targets, indicators and instruments. Let me start by discussing the goal of monetary policy. Price stability and full employment are often mentioned as possible goals of monetary policy. Research in recent years and practical experience during the postwar period have shown that an explicit monetary policy goal of full employment leads to a high rate of inflation, while an explicit price-stability goal alone does not result in lower rates of employment or growth. ${ }^{4}$ In the medium and long term there is evidence that monetary policy can only systematically affect nominal variables and not real ones. Therefore monetary policy can only have nominal variables as useful goals. Price stability will provide the best environment for efficient resource allocation and optimal growth. More and more countries have also assigned priority to the goal of price stability. Price stability can also be seen as the goal of the previous fixed exchange rate regimes in Europe, since one purpose of the fixed exchange rate was to ultimately force domestic inflation to conform with the low and stable German inflation. The discussion that follows is based on the assumption that price stability is the goal of monetary policy.

For several reasons it seems important to make the price-stability goal specific and

\footnotetext{
${ }^{3}$ See Bernanke and Miskkin (1992).

${ }^{4}$ See for instance Alesina and Summers (1993).
} 
precise. A precisely defined goal may reduce the uncertainty about monetary policy that a forced switch to a flexible exchange rate in all likelihood has caused. A precisely defined goal means a stronger commitment to monetary policy and can increase its credibility. A precisely defined goal makes it possible to monitor how well the goal is being met and to criticize the central bank directly, even holding it responsible, in the event the goal is not met. A precisely defined goal can also help to stabilize inflation expectations.

Against this background, it seems suitable to define price stability as an interval for the future price level or its rate of change, where the price level in turn is defined by the most commonly known price index, the consumer price index. Several countries have recently specified explicit inflation targets, for instance Britain, Finland and Sweden, following earlier examples of Canada and New Zealand. (See Freedman (1993) for a discussion of the Canadian experience of inflation targets, and for references to the relevant literature.)

Both theory and practical experiences indicate that institutional reform can enhance the credibility of the price-stability goals by: establishing price stability as the goal of monetary policy; by giving the central bank the independence that will enable it to achieve the goal and resist short-term pressures and special interest groups; and by holding the Board of Governors and management of the central bank accountable if the goal is not met.

Although there is evidence that monetary policy in the medium and long term can systematically affect only nominal variables, there is certainly evidence that monetary policy has effects on real variables, output and employment, in the short run. Therefore, monetary policy may stabilize or destabilize short-run fluctuations in output and employment, although it cannot systematically affect average output and employment in the medium and long run. This fact is not an argument against price stability as a goal for monetary policy. On the contrary, a credible price-stability goal is likely to make monetary policy more effective in stabilizing short-run output fluctuations, for two reason.

First, a price-stability policy implies an automatic stabilization of aggregate demand shocks. An increase in aggregate demand that leads to increased inflation will be met with a monetary contraction; vice versa for a decrease in aggregate demand. Second; it is likely that long-run credibility for a price-stability policy gives central bank more discretion to stabilize output in the short run, as discussed in Bernanke and Mishkin (1992). ${ }^{\mathrm{s}}$ Without such long-run credibility a short-run monetary expansion may be interpreted by the private sector as the beginning of an extended period of monetary expansion. There-

\footnotetext{
${ }^{5}$ See also Hörngren and Lindberg (1993).
} 
fore it may result in increased inflation expectations and increased wages, prices and long-term interest rates. This may both dampen the initial stimulating effect on output and lock the economy into a situation with high inflation. With long-run credibility, a short-run monetary expansion rate will not lead to increased inflation expectations and their accompanying negative eflects.

As examples of this, Germany and the United States seem to have established good long-run credibility for a price-stability policy, with low long interest rates and low longrun inflation expectations. This should imply considerable discretion in the short-run. Consistent with this, the United States has been able to meet the latest recession with a very expansionary monetary policy with very low short-term real interest rates, without any rise in long-run inflation expectations and long-term interest rates. Britain and Sweden, in contrast, seem to have lower long-run credibility for their price-stability policy, which shows up in higher long-term interest rates and higher long-run inflation expectations. Monetary expansion after the pound and the krona were floated indeed seem to have resulted in increased inflation expectations, as will be further discussed below in section 7. The scope for short-run monetary policy to stabilize output without endangering price stability seems smaller in Britain and Sweden than in German and the United States.

After this discussion of the goal of monetary policy, let me go on to discuss intermediate targets. Since the central bank has only indirect control over the price level, and since the latter reacts with "long and variable lags" to monetary policy measures, it may be desirable to select an intermediate target. An ideal intermediate target has a high correlation with the goal but is much easier to control and monitor. Thus, monetary policy is made easier if it is focused on the intermediate target. It is easy to monitor how well the central bank meets the intermediate target and the bank can more readily be held accountable if the intermediate target is not met. But the problem, not surprisingly, is that it is difficult to find an ideal intermediate target.

A fixed exchange rate towards a currency with a low and stable inflation can be seen as an intermediate target to achieve price stability. However, fixed exchange rates do not seem a realistic possibility in Europe in the short or medium term, except for Austria and the Netherlands. Even if fixed exchange rates against a stable currency were feasible, they may be a rather inefficient means to price stability, as argued in Svensson (1994).

Various money supply aggregates (from the monetary base to $\mathrm{M} 3$ ) are common as intermediate targets. In the academic literature, such broader aggregates as nominal 
expenditure and nominal GDP have also been proposed as intermediate targets. ${ }^{\bullet}$ Here, however, there is a conflict; although more narrow money-supply aggregates are easier to control, they may be very weakly correlated with the goal, while broader aggregates correlate more closely with the goal but are more difficult to control. A special problem is the fact that money supply aggregates have in many cases exhibited great instability-in connection with financial innovations or changes in credit market regulations, for example.

Many observers have considered Germany's use of M3 as an intermediate target a model for other countries. ${ }^{7}$ A target for the annual change in M3 is calculated based on forecasts of the annual change in velocity and potential GNP, and on an explicit inflation goal. However, this procedure requires stable empirical estimates of demand for money and experience in forecasting the velocity. In the short term it may be difficult to judge whether velocities are sufficiently forecastable for monetary aggregates to serve as intermediate targets. ${ }^{8}$ One particular problem is that the change from a fixed exchange rate to a flexible rate may itself affect the demand for money, in which case estimates with data from the period with a fixed exchange rate will no longer be applicable. At least in the short term after the abandonment of the fixed exchange rates, it seems most likely that monetary aggregates will be important indicators but not intermediate targets.

This implies a very important role for indicators. Without an intermediate target, only indicators remain between the instrument and the goal. The central bank will then have to use available indicators to assess the state of the economy and the stance of monetary policy in order to decide whether the instrument need to be adjusted or not for achieving price stability.

The central bank will need indicators of inflation pressure, especially indicators that forecast inflation one to two years ahead, since this is probably about the lag between the price level and monetary policy measures. A number of indicators will obviously be necessary for this, including money and credit aggregates, output gaps, vacancies and unemployment, asset prices and a number of other indicators used in forecasting business cycles.

Indicators of inflation expectations will be of great interest rates, for at least two rea-

\footnotetext{
'See Friedman (1990), McCallum (1990) and Rogoff (1985).

'See Bernanke and Mishkin (1992).

'It is worth noting that Germany's financial market is less developed than many other countries and that Germany lacks alternatives to bank deposits for interest-based savings by households and small companies. This contributes to the relatively stability of the demand for money, which can be expected to exceed that in many other countries, where private bonds, National Debt Office accounts, money-market funds and other instruments have already been introduced.
} 
sons. Market expectations of inflation can be seen as the market's forecast of inflation, which should have information for the central hank's forecast of inflation. Market expectations of inflation in relation to announced inflation goals also indicate the degree of credibility of the goal. Indicators of monetary policy expectations, for instance market expectations of future overnight interest rates when the overnight rate is the policy instrument, should also be of obvious interest to the central bank.

Short and long term interest rates, in general the yield curve and its slope, are traditional indicators for monetary policy. In the rest of this paper I shall argue that the information in the yield curve is more conveniently presented by the corresponding forward rate curve, and I shall discuss how the forward rate curve can be used as an indicator of market expectations of future interest rates, inflation rates and currency depreciation rates.

\section{Yields to Maturity, Spot Rates and Forward Rates}

The standard yield curve displays bill and bond yields to maturity as a function of the time to maturity. As is well known, the bond yield depends on the coupon size, the "coupon effect." Yields for different coupons are therefore not comparable. To make yield curves comparable they need to be standardized. This can be done in several ways. The theoretically preferable way is to express the yield curve in terms of yields to maturity on zero-coupon bond yields, spot (interest) rates. For maturities below 12 months spot rates are directly available in the form of rates on Treasury bills which are zero-coupon bonds. For longer maturities zero-coupon bonds are usually not available for sufficiently many maturities and in sufficiently large issues to be sufficiently liquid. Therefore spot rates will have to be estimated from yields on coupon bonds. Also, even if there were quite a few longer-maturity zero-coupon bonds, one might still want to use the information in the coupon bond yields. See Appendix 1 for details on how spot rates can be estimated from data on coupon bonds.

A few markets for forward loans and investment exist for settlements within 1 year, whereas very few or no such markets exist for longer maturities. Therefore, in practice only implied forward interest rates are available. Implied forward interest rates are derived from spot rates, since a forward investment with specific settlement and maturity dates can be reproduced by a sale and a purchase of zero-coupon bonds: a sale of a bond maturing on the forward contract's settlement date and a purchase of bonds of the same market value that matures on the forward contract's maturity date. The implied forward 
rate is the return on such a readjustment of a bond portfolio.

The algebra of spot and forward rates is easiest if all rates are continuously compounded. 9 Let $i(t, T)$ be the continuously compounded spot rate for a zero coupon bond traded at time $t$, the trade date, that matures at time $T>t$, the maturity date. Let $f\left(t, t^{\prime}, T\right)$ be the (implied) forward rate on a forward contract concluded at time $t$, the trade date, for an investment that starts at time $t^{\prime}>t$, the settlement date, and ends at time $T>t^{\prime}$, the maturity date. Then the forward rate is related to the spot rates according to

$$
f\left(t, t^{\prime}, T\right) \equiv \frac{(T-t) i(t, T)-\left(t^{\prime}-t\right) i\left(t, t^{\prime}\right)}{T-t^{\prime}} .
$$

That is, the forward rate for a one-year investment with settlement in 4 years $\left(t^{\prime}-t=4\right.$ years) and maturity in 5 years ( $T-t=5$ years) ("the 1-year forward rate 4 years from now $\left.^{n}\right)$ is equal to 5 times the 5-year spot rate minus 4 times the 4-year spot rate.

The instantaneous (-maturity) spot rate (in practice the over-night rate) is defined as

$$
i(t) \equiv \lim _{T \rightarrow t} i(t, T)
$$

and the instantaneous(-maturity) forward rate is defined as

$$
f\left(t, t^{\prime}\right) \equiv \lim _{T \rightarrow t^{\prime}} f\left(t, t^{\prime}, T\right) .
$$

The finite-maturity forward rate $f\left(t, t^{\prime}, T\right), T>t^{\prime}$, will be the average integral of the instantaneous forward rates with settlement between $t^{\prime}$ and $T$,

$$
f\left(t, t^{\prime}, T\right)=\frac{\int_{\tau=t^{\prime}}^{T} f(t, \tau) d \tau}{T-t^{\prime}}
$$

Instantaneous forward rates and finite-maturity spot rates are related as marginal and average cost of production, when the time to maturity is identified with quantity produced. The spot rate $i(t, T)$ at time $t$ with maturity at time $T$ is identical to the average of the instantaneous forward rates with settlements between the trade date $t$ and the maturity date $T$,

$$
i(t, T) \equiv \frac{\int_{r=t}^{T} f(t, \tau) d \tau}{T-t}
$$

\footnotetext{
${ }^{9}$ The continuously compounded apot rate $i(t, T)$ and the annually compounded spot rate $\tilde{i}(t, T)$ ase related by $\bar{i}(t, T)=\exp [i(t, T)]-1$ and $i(t, T)=\ln [1+\bar{i}(t, T)]$.
} 
Equivalently, the forward and spot rates fulfill the relation,

$$
f(t, T) \equiv i(t, T)+(T-t) \frac{\partial i(t, T)}{\partial T},
$$

which is the standard relation between marginal and average cost, with time to maturity $T-t$ corresponding to quantity produced. Hence, when looking at spot and forward rates we shall recognize sometimes the familiar shapes known from textbooks of microeconomic theory.

Figure Ia shows actual market bond yields and estimated spot and forward rates for France, for the trade date September 22, 1993. The squares show quotes of the overnight rate, Treasury bill yields and government bond yields, annually compounded and expressed in percent per year, and plotted against the maturity date. ${ }^{10}$ The dashed curve shows estimated spot rates plotted against the maturity date. The solid curve shows estimated instantaneous forward rates plotted against settlement (and maturity, since the two coincide for instantaneous forward rates). The forward rates approach a constant value for long maturities, marked by a horizontal line with long dashes. Error bars on the spot and forward rate curves denote 95 percent confidence intervals. See Appendix 1 for details on the estimation.

We see that the French spot curve on September 22, 1993, had a U-shape somewhat similar to the standard shape of average cost curves in microeconomics. Consequently the forward rate curve has a shape somewhat similar to the standard shape of marginal cost curves. The spot and forward rate curves start for zero time to maturity in the same point, the forward rate curve lies below the spot rate curve while the spot rate is decreasing in the time to maturity, the forward rate curve cuts the spot rate curve at the latter's minimum, and the forward rate curve lies above the spot curve when the latter is increasing. When for long times to maturity the forward rate becomes constant, the spot rate asymptotically approaches the same constant.

Since spot rates and forward rates can be derived from each other, they contain the same information. Using forward rates instead of spot rates is hence just presenting the same information in a different way. Using forward rates is an advantage when the emphasis is on expected future time paths of relevant variables rather than expected future time averages of these variables.

Next I shall discuss how forward rates can help to infer market expectations about

\footnotetext{
${ }^{10}$ The rates in the graphs are annually compounded, since that is the standard way to express interest rates, even though the equations and computalions are easiest with continuously compounded rates.
} 
future interest rates, inflation rates and future currency depreciation rates.

\section{Expected Future Interest Rates}

Under subjective certainty (perfect foresight, or point expectations) the forward rate $f\left(t, t^{\prime}, T\right)$ for a given settlement date $t^{\prime}$ and maturity date $T$ will equal the expected future spot rate $i\left(t^{\prime}, T\right)$ with trade date equal to the forward contract's settlement date and maturity date the same as the forward contract. Thus, the instantaneous forward rate will equal the expected future instantaneous spot rate (the future overnight rate).

Why is this? The reason is that a forward contract that involves lending at a future date, the settlement date, can be financed at the settlement date by borrowing on the spot market at the settlement date. Then the difference between the predetermined forward rate and the spot rate determined on the settlement date, $f\left(t, t^{\prime}, T\right)-i\left(t^{\prime}, T\right)$, is the excess (nominal) return on the forward contract. Under subjective certainty that excess return must be zero.

Under subjective uncertainty, the excess return on the forward contract is uncertain at the trade date, since the future spot rate is uncertain. Whether the forward rate equals the expected future spot rate then simply boils down to whether the expected excess return on the forward contract is zero or not. The expected excess return on the forward contract is the forward term premium, $\varphi\left(t, t^{\prime}, T\right)$. Hence, the expected future spot rate is the forward rate less the forward term premium,

$$
E_{t} i\left(t^{\prime}, T\right) \equiv f\left(t, t^{\prime}, T\right)-\varphi\left(t, t^{\prime}, T\right)
$$

Hence, whether the forward rate indicates the expected future spot rate is simply a matter of the size and the sign of the forward term premium.

Older theories of the term premium include the liquidity preference theory, which implies a positive holding period term premium (see below), and the preferred habitat theory, according to which the term premium for different settlements depend on relative supply and demand from investors with different horizons. More recent asset pricing theory (see Shiller (1990) and Svensson (1993b)) explains each premium as depending upon the covariance of the relevant real excess return with the real return on the market portfolio (CAPM), real consumption (consumption-based CAPM), or the marginal rate of real consumption (general asset pricing model). From the more recent theories there seems to be no prior as to the sign and magnitude of the term premium. 
The discussion of term premia in the literature is complicated by the fact that there are actually three different (but related) term premia that need to be distinguished (Shiller (1990)). Aside from the forward term premium there is the holding period term premium (the expected excess return of holding a long bond a short period over the short interest rate) and the rollover term premia (the expected excess return of holding a long bond to its maturity over the return from rolling over a short bond to the long bond's maturity) (see Appendix 2 for precise definitions). The literature has mostly discussed holding period term premia for, say, 10-year bonds held for 1 year. This premium is 9 times the forward term premium with settlement in 1 year and maturity in 10 years. This is a combination of settlement and maturity that is hardly relevant for monetary policy; the forward term premia that are relevant would rather have settlement in 2-4 years, say, and maturity one year after. There are very few estimates in the literature of forward term premia with that combination of settlement and maturity. ${ }^{11}$

McCulloch (1975, Table 6) reports average (unconditional) forward term premia for US monthly Treasury bills and Treasury bonds data for the period 1946-1966. For settlement in $1-5$ years and maturity 1 year later he finds positive but small premia, $0.03-0.10$ percent per year, not significantly different from zero. For settlement in 10 years and maturity 1 year later the premium is $\mathbf{- 1 . 0 9}$ percent per year, not significantly different from zero.

For the period 1952-1987 I have estimated unconditional forward term premia on a database presented in McCulloch (1990), for settlement in 1-4 years and maturity 1 year later. ${ }^{12}$ The result is displayed in Table 1 . The premia are fairly small and negative, between -0.10 and -0.62 percent per year, not significantly different from zero (the premium for settlement in 4 years is close to being significant, though)..$^{13}$

Conventional wisdom says that yield curves often have a positive slope (that is, the yield spread between long and short rates is positive). This is sometimes taken as implying positive term premia. That implication is not correct, though. Term premia can be small or even zero even if the yield spread is positive: Suppose short rates are increasing over the sample period (this is the case for samples ending with the 1980s). Suppose term

\footnotetext{
${ }^{11}$ Campbell and Shiller (1991) test and reject the expectations hypohtesis for a number of different combinations of different maturities and settlement. They do not report eatimates of term premia, though. Frachot and Lesne (1993) derive term premia in a model of the term structure with stochastic conditional volatility and are able to explain the empirical results of Campbell and Shiller (1991).

${ }^{12}$ This is the same dataset that Campbell and Shiller (1991) uses.

${ }^{13}$ For US data, for settlement in 2-4 years and maturity 1 year later, Fama and Bliss (1987) cannot reject the bypothesis that forward rates forecast future interest rates and that forward term premia are zero.
} 
premia are zero, so long rates equal expected average short rates up to the long bond maturity. If short rates are expected to increase, expected future short rates and hence current long rates are of course higher than current short rates.

To check this, I have estimated the average yield spread between 1-10 year maturities and the 3-month maturity, on McCulloch's (1990) dataset. The result is reported in Table 2. The average yield spread is positive, between 0.37 and 0.81 percent per year, and significantly different from zero. This is so even though term premia are small and negative.

The premia reported here are average, unconditional, term premia. It is, however, the conditional time-varying premia that are relevant in (4.1). Even if unconditional term premia are small, it is possible that time-varying term premia can be sometimes large. If time-varying premia are forecastable and economically significant, forward rates should be adjusted by the premia in order to infer expected future interest rates. Then the time-varying premia should be estimated simultaneously with the spot and forward rates. If time-varying term premia are not forecastable, the forward rates should be adjusted with the unconditional term premia. The estimates of these reported here indicate that they are rather small, though. However, even if the term premia were large, if they were relatively stable, shifts over time in unadjusted forward rate curves would still contain information, even if the level of the curves would be less reliable.

In the rest of the paper I shall assume that the term premia relevant for monetary policy are negligible, and that forward rates indicate expected future spot rates.

Treasury bill and government bond yields fluctuate quite a bit from day to day, perhaps depending upon temporary excess demand or supply for different maturities. Consequently estimates of spot and forward rates fluctuate quite a bit from day to day. I do not want to assume that these sbort-run fluctuations necessarily reflect short-run changes in expected future spot rates. Instead the assumption is that forward rates indicate expected future spot rates when tbese short-run fluctuations are filtered out. Therefore, throughout one should use for instance moving averages over one or a few weeks, rather than estimates for a particular day. For convenience only, tbe examples in this paper will refer to estimates for single dates.

Figure $1 b$ shows spot rates (dashed curves) and forward rates (solid curves) on September 22, 1993, for France (thick curves) and Britain (thin curves). Consider expectations of future monetary policy for France, as manifested by the overnight rate. We see that the expected overnight rate is expected to be lowered to almost 5 percent per year at the 
end of 1995. From 1996 onwards the over-night rate is expected to increase to about 7 percent per year by year 2001. For Britain, the overnight rates are expected to increase from a bit more than 5 percent per year to reach 8 percent per year in year 2000 .

How should such expected increases in the overnight rate be interpreted? Could they be interpreted as an expected future monetary contraction because of expected future inflation? Hardly. If the central bank is expected to react to higher inflation with a monetary contraction this would be incorporated into price-setting behavior, in which case the higher inflation and resulting contraction would not occur, and hence not be expected to occur. An expected increase in overnight rates might reflect a return to normal short real rates if these are currently abnormally low. Current French and British short real rates do not seem to be abnormally low, though. ${ }^{14}$ Instead it seems that the expected increase in overnight interest rates must be interpreted as an expected accommodation of the central bank to a situation of higher inflation, higher money growth, and higher interest rates due to lower demand for real money balances. Inflation expectations will be further discussed in the next section.

Whereas the forward rates indicate the expected time-path of future short interest rates, the spot rate for a particular maturity indicates the expected average short rates up to that maturity. The British spot rate of 7 percent per year for maturity in year 2000 is hence the average short rate between 1993 and 2000 .

What about expected future interest rate differentials across countries? From (4.1) and its foreign analog we get that the expected future interest rate differential between the domestic and foreign country fulfills

$$
E_{t} i\left(t^{\prime}, T\right)-E_{t} i^{*}\left(t^{\prime}, T\right) \equiv f\left(t, t^{\prime}, T\right)-f^{*}\left(t, t^{\prime}, T\right)-\left[\varphi\left(t, t^{\prime}, T\right)-\varphi^{*}\left(t, t^{\prime}, T\right)\right]
$$

where foreign variables are denoted by an asterisk. The expected future interest rate differential equals the difference between the domestic and foreign forward rates less the difference between the domestic and foreign forward term premia. If the premia are of the same sign and magnitude they will hence cancel.

Assuming that the premia are either negligible or that they cancel, we can use the difference between the French and British forward rate curves in Figure $1 b$ to infer the

\footnotetext{
${ }^{14}$ Bank of England (1993a) displays a real forward rate curve (derived from the British index-linked gits) that does not indicate an expected rapid increase in short real interest rates. In May 1993 the real forward rate for settlement in 2 years was 3 percent per year. It increases slowly with settlement and reaches 4 percent per year for settlement in about 14 years.
} 
expected future interest rate differential between the two countries. The differential is obviously expected to go from almost minus 2 percentage points to plus 2 percentage points in about 4 years.

\section{Expected Future Inflation Rates}

Let $r(t, T)$ and $\pi(t, T)$ denote the real spot interest rate and the inflation rate, respectively, between times $t$ and $T, T>t .{ }^{15}$ Under subjective certainty the Fisher equation holds. That is, the future inflation rate $\pi\left(t^{\prime}, T\right)$ between time $t^{\prime}$ and $T$ that is expected at time $t, t<t^{\prime}<T$, is equal to the difference between the expected future nominal and real spot rates between times $t^{\prime}$ and $T, i\left(t^{\prime}, T\right)-r\left(t^{\prime}, T\right)$. Under subjective certainty the nominal forward rate equals the expected nominal future spot rate. Furthermore, if there is market for real bonds, the real forward rate equals the expected real future spot rate. Hence, the expected future inflation rate equals the difference between the nominal and real forward rates.

With subjective uncertainty, the expected future inflation rate is no longer necessarily equal to the difference between expected future nominal and real spot rate. Instead an inflation risk premium $\theta\left(t, t^{\prime}, T\right)$ enters, so we have

$$
\mathrm{E}_{t} \pi\left(t^{\prime}, T\right) \equiv \mathrm{E}_{t} i\left(t^{\prime}, T\right)-\mathrm{E}_{t} r\left(t^{\prime}, T\right)-\theta\left(t, t^{\prime}, T\right)
$$

The inflation risk premium is the expected real excess return on nominal bonds over real bonds. According to standard theory it depends on the covariance between that excess return and the return on the market portfolio (CAPM), consumption (consumption-based CAPM) or the marginal rate of substitution (general asset-pricing model) (see Svensson (1993b)). Furthermore, we have seen in (4.1) that the expected nominal future spot rate equals the nominal forward rate less the (nominal) term premium. Hence, the expected future inflation rate is related to the forward rate as

$$
E_{t} \pi\left(t, t^{\prime}, T\right) \equiv f\left(t, t^{\prime}, T\right)-E_{t} r\left(t^{\prime}, T\right)-\varphi\left(t, t^{\prime}, T\right)-\theta\left(t, t^{\prime}, T\right)
$$

With a market for real bonds, as in Britain, the expected future real spot rate is related

\footnotetext{
${ }^{15}$ The inflation rate $x(t, T)$ is defined as $x(t, T)=\frac{\ln [P(T) / P(t)]}{T-t}$, where $P(t)$ is the price level at time $t$.
} 
to the real forward rate, $g\left(t, t^{\prime}, T\right)$, via the real (forward) term premium, $\psi\left(t, t^{\prime}, T\right)$,

$$
\mathrm{E}_{t} r\left(t^{\prime}, T\right) \equiv g\left(t, t^{\prime}, T\right)-\psi\left(t, t^{\prime}, T\right)
$$

It follows that the expected future inflation rate can be written

$$
\mathrm{E}_{\mathrm{t}} \pi\left(t, t^{\prime}, T\right) \equiv f\left(t, t^{\prime}, T\right)-g\left(t, t^{\prime}, T\right)-\left\{\varphi\left(t, t^{\prime}, T\right)-\psi\left(t, t^{\prime}, T\right)\right]-\theta\left(t, t^{\prime}, T\right)
$$

the difference between the nominal and real forward rates, less the difference between the nominal and real term premia, less the inflation risk premium.

If there is a market for real bonds, expression (5.4) can be used. If the nominal and real term premia are of the same sign and magnitude they will cancel. The inflation risk premium should be small in an economy with real bonds, since with real bonds in the market portfolio the correlation between inflation and the return on the market portfolio should be less. Then expression (5.4) should he a rather reliable measure of expected future inflation rates. ${ }^{16}$

Without a market for real bonds, only expression (5.2) can be used. The estimated expected future inflation rate will be contingent upon an assumed expected future real interest rate.

As mentioned the inflation risk premium depends on the covariance hetween the excess real return on nominal bonds over real honds and the return on the market portfolio, consumption or the marginal rate of substitution, depending upon which asset pricing model is used. The excess return is simply the negative of the rate of inflation. The inflation risk premium then depends on the covariance between inflation and the variables mentioned. Whether the inflation premium is positive or negative depends (in CAPM) on whether inflation is negatively or positively correlated with the return on the market portfolio. A priori it is not obvious which sign the inflation risk premium will have. Regardless of the sign, the correlation between inflation and the return on the market portfolio is probahly not large, in which case the inflation risk premium is unlikely to he large.

In the rest of the paper I shall assume that the inflation risk premium is negligible.

Assume that the expected future real spot rate for France and Britain will he between

\footnotetext{
${ }^{16}$ Bank of England (1993a,b) reports inflation expectations for Britain by subracting a real implied forward rate curve from a nominal forward rate curve. The real forward rate curve is estimated from yields on the British index-linked gilts. Woodward (1990) has previously used data on the index-linked gilts to compute the term structure of inflation expectations for Britain.
} 
3 and 4 percent from 1996 onwards. ${ }^{17}$ Then in Figure $1 \mathrm{~b}$ we conclude that the expected French inflation rate for 1996 is $1.5-2.5$ percent per year, since the forward rate for that year is about 5.5 percent per year. The expected inflation rate rises somewhat to $3-4$ percent per year around year 2001. The expected future British inflation rate is 3.5-4.5 percent per year in 1996 and increases further to 4-5 percent per year around year 2001. The difference between the nominal spot rate for given maturity and an assumed real spot rate would indicate the expected average inflation rate for that maturity. The difference between the nominal forward rate for a given settlement and an assumed future real rate indicate the expected future inflation rate at the time of the settlement. Hence, the forward rate curve indicate the expected time-path of the inflation rate, whereas the spot rate curve indicates the expected average future inflation.

What about expected future inflation differentials across countries. From (5.2) and its foreign analog follows

$$
\begin{aligned}
& \mathrm{E}_{t} \pi\left(t, t^{\prime}, T\right)-\mathrm{E}_{\mathrm{l}} \pi^{*}\left(t, t^{\prime}, T\right) \equiv f\left(t, t^{\prime}, T\right)-f^{*}\left(t, t^{\prime}, T\right)-\left[\mathrm{E}_{\mathrm{s}} r\left(t^{\prime}, T\right)-\mathrm{E}_{\mathrm{g}} r^{*}\left(t^{\prime}, T\right)\right] \\
& -\left[\varphi\left(t, t^{\prime}, T\right)-\varphi^{*}\left(t, t^{\prime}, T\right)\right]-\left[\theta\left(t, t^{\prime}, T\right)-\theta^{*}\left(t, t^{\prime}, T\right)\right] \text {. }
\end{aligned}
$$

The expected inflation rate differential is equal to the difference between the forward rates, less the difference between the expected real rates, less the difference between the term premia, less the difference between the inflation risk premia. If expected future real rates, term premia and inflation risk premia are similar across the countries, the forward rate difference is a good indicator of the expected future inflation differentials.

In Figure 1b, for 1996 and a few years after, the expected inflation for Britain is about 2 percentage points higher than for France.

\section{Expected Future Currency Depreciation Rates}

Under subjective certainty the expected future depreciation rate between time $t^{\prime}$ and time $T>t^{\prime}$ of the domestic currency relative to the foreign currency, $\delta\left(t^{\prime}, T\right)$, must equal the

${ }^{17}$ This is consistent with the real forward rate curve presented jn Bank of England (1993a). Note that it does not make sense to assume a given expected real except at least a couple of years into the future. In the short run there is considerable inertia in the price level and the inflation rate. With some simplification: in the short run the inflation is sticky and the real rate adjusts to the nominal rate; the medium and long run the real rate is sticky and the nominal rate adjusts to the expected inflation rate. 
expected future interest rate differential, $i\left(t^{\prime}, T\right)-i^{*}\left(t^{\prime}, T\right) .{ }^{18}$ Under subjective certainty the forward foreign exchange risk premium, $\xi\left(t, t^{\prime}, T\right)$, enters into the relation,

$$
\mathrm{E}_{t} \delta\left(t^{\prime}, T\right) \equiv \mathrm{E}_{t} i\left(t^{\prime}, T\right)-\mathrm{E}_{t} i^{-*}\left(t^{\prime}, T\right)-\xi\left(t, t^{\prime}, T\right)
$$

so the expected future currency depreciation rate equals the expected future interest rate less the forward foreign exchange risk premium.

The forward foreign exchange risk premium is the expected excess nominal return on domestic currency bonds over foreign currency bonds. It depends on the covariance with the nominal return on the market portfolio (CAPM) or the nominal marginal rate of substitution (general asset-pricing model) (see Svensson 1993c)).

Uncovered interest parity is the same thing as zero foreign exchange risk premia. Uncovered interest rate parity is usually empirically rejected, except for the franc/mark exchange rate (see Rose and Svensson (1993), for instance). However, attempts to estimate the size of foreign exchange risk premia have usually resulted in very small premia (see Hodrick (1987) and Marston (1993) for surveys).

In the rest of the paper I shall assume that the foreign exchange risk premium is negligible.

From (4.2) follows that the expected currency depreciation rate fulfills

$$
E_{t} \delta\left(t^{\prime}, T\right)=f\left(t, t^{\prime}, T\right)-f^{*}\left(t, t^{\prime}, T\right)-\left[\varphi\left(t, t^{\prime}, T\right)-\varphi^{*}\left(t, t^{\prime}, T\right)\right]-\xi\left(t, t^{\prime}, T\right)
$$

the difference between the forward rates, less the difference between the term premia, less the foreign exchange risk premium.

If the term premia are assumed to cancel, and the foreign exchange risk premium is assumed to be negligible, the vertical distance between the French and British forward rate curves show the expected future depreciation rate of the franc relative to the pound. The vertical distance between the French and British spot curves shows the average rate of depreciation up to the maturity date.

Figure $1 c$ shows the expected future depreciation rate (dashed curve) and expected

\footnotetext{
${ }^{18}$ Let $e(t)$ denote the log exchange rate (log of units of domestic currency per unit of foreign currency). Then the domestic currency depreciation rate $\delta(t, T)$ is defined as

$$
\delta(t, T) \equiv \frac{e(T)-e(t)}{T-t}, T>t
$$
}


future accumulated log depreciation (solid curve) of the franc relative to the pound. ${ }^{10}$ Hence the dashed curve is the slope of the solid curve. We see that the franc is expected to depreciate initially but appreciate eventually by more than 10 percent in the next 10 years.

\section{Comparison of Monetary Policies}

This section compares monetary policies in France, Germany, Britain, Sweden and the United States with the help of graphs of spot and forward rates as well as of expected future exchange rates. Figures $2 a, b$ and $3 a, b$ show spot and forward rates by country and by trade date. The six trade dates are September 14 and 21 for 1992 (before and after Black Wednesday, September 16, 1992); February 5, May 7, August 2 (immediately after the July crisis 1993) and September 22 for 1993 . The first five dates are chosen to coincide with those for which Bank of England's model Inflation Report report British forward rates (Bank of England $(1993 a, b)$ ). The British forward rates estimated here correspond closely to those reported by Bank of England, although they are computed with different methods. ${ }^{20}$

Spot and forward rates have been estimated with the help of selected Treasury bill and government bond yields for each trade date, with a method described in Appendix 1. The estimates should really be done with all the reasonably liquid bills and bonds, and with a fair amount of detailed institutional knowledge of each country's bill and bond market. A few different estimation methods should also be tried. The graphs presented here should therefore be considered as indicative only.

Graphs of forward rates lend themselves very well to studies of particular events, and the graphs should really be interpreted by researchers with detailed knowledge of monetary policy events in each country. Lacking such knowledge for countries other than Sweden, I will here only present some broad impressions, and instead invite specialists on

${ }^{10}$ The expected accumulated log depreciation is given by

$$
\mathrm{E}_{1} e(T)-e(t)=\mathrm{E}_{1} \delta(t, T)(T-t), T>t .
$$

Under the assumption of a negligible foreign exchange risk premium (uncovered interest parity) it fulfills

$$
E_{1} e(T)-e(t)=\left[i(t, T)-i^{*}(t, T)\right](T-t) .
$$

\footnotetext{
${ }^{30}$ Bank of England computes forward rates from a par yield curve, the estimation of which is described in Bank of England (1990) and Mastronikola (1991).
} 
each country for more detailed interpretation.

Consider Figure $9 a$ which shows instantaneous forward rates by country. Central banks control interest rates at the shortest maturities (overnight or weekly rates, say). Central banks therefore control the left end-point of each forward rate curve (the shortest forward rate coincides with the shortest spot rate). The rest of the curves is determined by the market, and can be interpreted as the market's expectations of future short rates, hence of future monetary policy as it is manifested in the short rates central banks set. The excess of the forward rates over a given expected future real spot rate can be interpreted as the expected future inflation, and differences between countries' forward rates can be interpreted as expected future currency depreciation rates, all under the maintained assumption that the relevant premia are either negligible or cancel. Even if the premia are not negligible or do not cancel, as long as they are stable over time, shifts in the curves convey information even if levels cannot be interpreted.

However, let me repeat that I do not want to assume that day-to-day fluctuations in estimated forward rates should be interpreted in this way, instead the interpretation concerns averages over one or a few weeks, say. The estimated spot and forward rates to be discussed are nevertheless for simplicity from six single dates only, which is another reason why only broad impressions rather than a detailed interpretation is presented.

Figure 3a shows that forward rate curves in general have shifted down during the last year. For the United States longer forward rates have fallen more than shorter, whereas the opposite is the case for the other countries. The British experience is interesting (it is also discussed in Bank of England's Infiation Report). The lowering of short rates after Black Wednesday was followed by a considerable increase (several percentage points) in long forward rates. Only recently have long forward rates come down to where they were irmmediately before Black Wednesday. One interpretation is that monetary expansion after Black Wednesday, with limited credibility due to Britain's inflation history and lack of independence of Bank of England, led to a considerable increase in long run inflation expectations. For France lower short rates have not been followed by increases in the long forward rates. Only recently have the long forward rates come down somewhat. For Sweden the lowering of short rates have, as for Britain, been followed by increases in long forward rates, and only during the last summer have they come down to where they were immediately before Black Wednesday.

A comparison with Figure $2 a$ for Britain and Sweden shows that the spot rates give a different interpretation than the forward rates. The long spot rates had come down 
below the levels of September 14, 1992, already in February, 1993, and they have fallen considerably below since. The long spot rates, being the average forward rates from the trade date up to the maturity, are influenced also by expected interest rate movements in the near term, whereas long forward rate have filtered out the effects of short-term expectations. To the extent that the focus is on expected interest and inflation rates in years a few years into the future, the forward rates are more relevant than the spot rates. Indeed, since monetary policy has effects on the price level with a lag of, say, one or two years, in monetary policy issues it should be frequent to look beyond the first year or two. Looking at the spot rates in such a situation may actually be misleading, as this example shows.

Figure $3 b$ shows forward rates by trade dates. Especially in the spring of 1993 the countries fall into two categories. France, Germany, and the United States fall in one category, with similar relatively low long forward rates. Britain and Sweden fall into another category, with significantly higher long forward rates. This pattern is less clear in the fall of 1993, with the long forward rates of France and Britain falling in between those of Sweden and the United States.

I interpret this as indicating that there is higher credibility for price-stability monetary policy in France, Germany, and the United States than in Britain and Sweden. ${ }^{21}$ In Britain and Sweden the lowering of short rates have lead to increased long forward rates, which only recently have come back to the same levels as before Black Wednesday. The United States's high credibility has allowed a very expansionary monetary policy in the short run with very low short nominal and real rates, without resulting in increased long forward rates due to increased long-run inflation expectations. Instead the long forward rates have even come down during the last year. Germany's long forward rates have also come down since September 1992. Whereas France in the spring of 1993 had forward rates very similar to Germany's, after the July crisis the long forward rates have risen somewhat above Germany's, which if sustained might be interpreted as indicating some market doubts about France's long-run inflation outlook.

Figure fa shows expected future mark exchange rates for the franc, the pound, the krona and the dollar, expressed as accumulated log depreciation from September 14, 1992. The left end-point of each curve shows the spot exchange rate on the corresponding trade date. The rest of each curve shows the expected accumulated future log depreciation

\footnotetext{
T1The reasons for the high credibility of price stability in the United States are discussed by Goodfriend (1993).
} 
calculated from the differences between forward rates in Figure 3b. Therefore Figure 4a simply shows the exchange rate expectations that are consistent with the forward in terest rates and the spot exchange rate on each trade date. The franc had in September 1993 depreciated a few percent relative to the mark, but there were no expectations of further depreciation. The pound had in September 1993 depreciated quite a bit, some appreciation was expected in the short term, and in the long run further depreciation is expected. For the krona, it appears that during the September 1992 crises, the expected devaluation was about 10 percent (see the kink at 10 percent for the curves of September 14 and 21 in 1992). After the krona was floated in November 1992 it has depreciated rapidly, more rapidly than expected, and in September 1993 further depreciation was expected. The dollar has fluctuated relative to the mark quite a bit, but there are no expectations of substantial future depreciation or appreciation.

\section{Conclusion}

In the new situation with flexible exchange rates, monetary policy in Europe will have to rely more on indicators than previously under fixed rates, especially since it will most likely be difficult, at least for some time, to find appropriate and reliable intermediate targets for monetary policy. Several different indicators will have to be used. One of the potential indicators, the (implied) forward interest rate curve, can be used to indicate market expectations of the time-paths of future short interest rates, monetary policy, inflation rates and currency depreciation rates.

The forward rate curve contains the same information as the spot rate curve, but it presents the information in a way that makes it easier to interpret for monetary policy purposes. Thus the forward rate curve separates market expectations for the short, medium and long term more easily than the spot rate curve. Since monetary policy measures have effects with "long and variable lags," looking beyond the short term is important in monetary policy. Using long spot rates or long bond yields instead of long forward rates can then give misleading impressions, since long spot rates and long bond yields include expectations of interest rate movements in the short term. In long forward rates expectations of interest rate movements in the short term have been filtered out.

Monetary policy in France, Germany, Great Britain, Sweden and the United States has been interpreted with the help of forward rates. The British and Swedish experience is similar in that long forward rates increased considerably after the pound and the krona were floated, and the long forward rates have come down to pre-September 1992 levels 
only recently. In contrast, monetary expansion and very low short-term interest rates in the United States has been followed by a fall in long forward rates. There is some indication of an increase in French long forward rates after the widening of ERM bands in August 1993. These developments have been be interpreted in terms of movements in long run inflation expectations. The developments and the interpretation in terms of inflation expectations are consistent with the idea that long-run credibility for a price-stability policy increases the scope for monetary policy to stabilize output and employment in the short run.

The paper has highlighted the role of term, inflation and foreign exchange risk premia in using forward rates as indicators of future interest rates, inflation rates and currency depreciation rates. The maintained assumption in the analysis of monetary policy in the five countries considered is that the relevant premia either cancel or are negligible. This maintained assumption has some empirical support. Estimates of average forward premia for settlement in a few years and maturity one year later indicate that the premia are small. Also, the conventional wisdom that upward sloping yield curves imply positive term premia is not correct, since the upward sloping yield curve may be explained by expectations of rising short rates over the sample. However, it is actually conditional timevarying premia, rather than unconditional average premia that are relevant. More research on and estimation of unconditional time-varying forward premia with these combinations of settlement and maturity is called for. The literature has usually considered other term premia, the holding period and rollover term premia, and other combinations of settlement and maturity. The literature has also frequently focused on testing the expectations hypothesis (the hypothesis of zero risk premia) rather than on actually estimating the size of the premia in order to judge whether the premia are economically as well as statistically significant.

If unconditional time-varying premia are non-negligible, that does not mean that forward rates cannot be used as indicators, only that the premia should be estimated simultaneously with the forward rates and then used to adjust the forward rates.

\section{A. Estimation of Spot and Forward Interest Rates}

The estimation of spot and forward rates follows McCulloch $(1971,1975)$ in fitting for each trade date a discount function (the price of a zero-coupon bond as a function of the time to maturity) to bill and bond price data, but it uses the functional form of Nelson 
and Siegel (1987) instead of McCulloch's cubic spline. ${ }^{22}$

Nelson and Siegel (1987) assume that the instantaneous forward rate is the solution to a second-order differential equation with two equal roots. Hence it can be written

$$
f(m ; \beta, \tau)=\beta_{0}+\beta_{1} \exp \left(-\frac{m}{\tau}\right)+\beta_{2} \frac{m}{\tau} \exp \left(-\frac{m}{\tau}\right)
$$

where $m \geq 0$ is the time to maturity in years, and where $\beta_{0}, \beta_{1}, \beta_{2}$ and $\tau$ are the parameters. The spot rate can be derived by integrating the forward rate according to (3.5). It is given by

$$
i(m ; \beta, \tau)=\beta_{0}+\left(\beta_{1}+\beta_{2}\right) \frac{1-\exp \left(-\frac{m}{\tau}\right)}{\frac{m}{\tau}}-\beta_{2} \exp \left(-\frac{m}{\tau}\right) .
$$

Let $i(0 ; \beta, \tau), f(0 ; \beta, \tau), i(\infty ; \beta, \tau)$ and $f(\infty ; \beta, \tau)$ denote the limits of the spot and forward rates when the time to maturity goes to zero and infinity, respectively. The spot and forward rates have the properties

$$
\begin{gathered}
i(\infty ; \beta, \tau)=f(\infty ; \beta, \tau)=\beta_{0} \text { and } \\
i(0 ; \beta, \tau)=f(0 ; \beta, \tau)=\beta_{0}+\beta_{1} .
\end{gathered}
$$

Furthermore, suppose there is a maximum or a minimum for the forward rate, that is, there is an $\hat{m} \geq 0$ such that the derivative $f_{m}(\hat{m} ; \beta, \tau)=0$, with $\hat{f}=f(\hat{m} ; \beta, \tau)$. Then,

$$
\begin{gathered}
\hat{f}=\beta_{0}+\beta_{2} \exp \left(\frac{\beta_{1}}{\beta_{2}}-1\right) \text { and } \\
\frac{\hat{m}}{\tau}=1-\frac{\beta_{1}}{\beta_{2}} .
\end{gathered}
$$

It follows that the parameters $\beta_{0}, \beta_{1}, \beta_{2}$ and $\tau$ can be computed recursively by $f(\infty)$, $f(0), \hat{f}$ and $\hat{m}$, which facilitates their interpretation and the choice of starting values in the estimation procedure.

The discount function is then given by

$$
d(m ; \beta, \tau)=\exp [-i(m ; \beta, \tau) m]
$$

\footnotetext{
${ }^{22}$ See Dahlquist and Svensson (1993) for a comparision of estimates of spot and forward rates with the simple functional form of Nelson and Siegel (1987) and the complex functional form of Longstaf and Schwartz (1992).
} 
For a given trade date, let there be $n$ coupon bonds $\left(c_{j}, m_{j}, p_{j}\right), j=1, \ldots, n$, where $c_{j}, m_{j}$ and $p_{j}$ denote, respectively, the coupon, the time to maturity and the observed price of bond $j$, which is assumed to have a face value of 100 units of domestic currency. If bond prices are not directly available, they are computed from the yields to maturity. For given parameters $(\beta, \tau)$ the model prices of the bonds, $P_{j}(\beta, \tau)$, are computed with the discount function evaluating each coupon payment:

For annual coupon payments, let $\tau_{j k}, k=1,2, \ldots, K_{j}$, denote the times for the coupon payments on bond $j$, where $K_{j}$ is the number of coupon payments. In the special case when $m_{j}$ is an integer, we simply have $\tau_{j k}=k$ and $K_{j}=m_{j}$. In the general case we have

$$
\begin{aligned}
\tau_{j k} & =m_{j}-\left[m_{j}\right]+k-1 \text { and } \\
K_{j} & =\left[m_{j}\right]+1
\end{aligned}
$$

where $\left[m_{j}\right]$ denotes the largest integer that is strictly smaller than $m_{j}$. The model price of each bond, $P_{j}(\beta, \tau)$, is the present value of the bond when the coupon payments and the face value are priced with the discount function,

$$
P_{j}(\beta, \tau) \equiv \sum_{k=1}^{K_{j}} 100 \cdot c_{j} d\left(\tau_{j k} ; \beta, \tau\right)+100 \cdot d\left(\tau_{j} K_{j} ; \beta, \tau\right), j=1, \ldots, n
$$

For semiannual coupon payments, that is, for Britain and the United States, these relations are accordingly modified.

The observed price is assumed to differ from the model price by an error term, $\epsilon_{j},{ }^{23}$

$$
p_{j}=P_{j}(\beta, \tau)+\epsilon_{j}
$$

The model prices are then fitted to the observed prices with non-linear least squares or with maximum-likelihood. The estimates in this paper are maximum likelihood. The $95 \%$ confidence intervals have been computed with the delta method and are heteroskedasticityconsistent.

Figure $A 1$ corresponds to Figure 1a, for France, September 22, 1993. It shows actual bond prices (squares), estimated bond prices with $95 \%$ confidence intervals (dots with error bars), and coupons (pluses). For this estimation the root mean square error is 0.28

\footnotetext{
${ }^{23}$ That model prices will not be exactly equal to observed prices would be a problem if the model was used to price financial instruments, since that would allow arbitrage (cf. Hull $(1993$, p. 398)). However, the purpose here is to provide spot and forward rates to be used as indieators for monetary policy, in which case small deviations between model and observed prices is of no significance.
} 
percent of the bonds's principal value. The maximum error is 0.68 percent of the face value of the 19-year bond maturing in year 2012. The root mean square error of yield errors is 0.13 percentage points. The parameters are $\beta_{0}=0.0746, \beta_{1}=-0.0060, \beta_{2}=-0.0571$ and $\tau=2.210$. For long maturities the spot and forward rates hence approach the level 7.46 percent per year continuously compounded, which corresponds to 7.75 percent per year annually compounded.

The estimates of the spot and forward rates in this paper has been done with the restriction that the estimated spot rate and forward rate for zero maturity and settlement should equal the quoted overnight rate (in practice, that $\beta_{0}$ and $\beta_{1}$ should sum to the quoted overnight rate). In some cases that has lead to a poor fit of the Treasury bill rates with maturity 3, 6 or 12 months. Then the zero-maturity spot and forward rate has been adjusted to give a better fit to the Treasury bill rates. In these cases the left end-points of the spot and forward rate curves of course differ from the quoted overnight rate. Figure $\mathrm{Ia}_{\mathrm{a}}$ is one such case. There the zero-maturity spot and forward rate has been set to is 7.1 percent per year annually compounded, which differ from the quoted overnight rate, about 7.5 percent per year annually compounded. This procedure has been followed since I have trusted the Treasury bill data more than the overnight rate data.

It is desirable that the estimated spot rates should fit the Treasury bill rates well since the latter are actual spot rates. There is no reason the estimated spot rates should equal the coupon bond yields, since the yields depend on the coupons. Therefore, the fact that the spot rates in Figure 1a deviate from the bond yields for long maturities does not indicate a bad fit.

Minimizing the squared deviations from Treasury bill and bond prices gives less weight to short-maturity yields, since prices are insensitive to yields for short maturities. Unrestricted estimates can then give fairly large deviations for short yields. That is the reason why I have imposed the restriction on estimated zero-maturity spot and forward rates. Alternatively, the price deviations can be weighted somewhat in favor of short maturities. Minimizing deviations from yields is of course an implicit strong weighting of short maturities. In general, the weighting should be motivated by the purpose of the estimation, especially in which maturity range most precision is desired.

Convergence was fast with reasonable starting values, especially when the parameters $\beta_{0}, \beta_{1}$ and $\beta_{2}$ were scaled by 100 .

See Dahlquist and Svensson (1993) for further discussion of these and related issues. 


\section{B. Three Different Term Premia}

As discussed in Shiller (1990) there are three kinds of term premia that have been discussed in the literature. The forward term premium $\varphi\left(t, t^{\prime}, T\right)$ is defined as

$$
\varphi\left(t, t^{\prime}, T\right) \equiv f\left(t, t^{\prime}, T\right)-\mathrm{E}_{t} i\left(t^{\prime}, T\right)
$$

The holding period term premium $\varphi_{h}\left(t, t^{\prime}, T\right)$ is defined as

$$
\varphi_{h}\left(t, t^{\prime}, T\right) \equiv \mathrm{E}_{\mathrm{t}} h\left(t, t^{\prime}, T\right)-i\left(t, t^{\prime}\right)
$$

where the holding period return $h\left(t, t^{\prime}, T\right)$ is the rate of return from holding a bond maturing at time $T$ from time $t$ to time $t^{\prime}$, which gives

$$
h\left(t, t^{\prime}, T\right) \equiv \frac{i(t, T)(T-t)-i\left(t^{\prime}, T\right)\left(T-t^{\prime}\right)}{t^{\prime}-t} .
$$

The rollover term premium $\varphi_{r}(t, T, m)$ is defined as

$$
\varphi_{r}(t, T, m)=i(t, T)-\frac{1}{n} \sum_{j=1}^{n} E_{t} i(t+(j-1) m, t+j m),
$$

where $m=\frac{T-t}{n}$ and $n$ is an integer, the number of times a bond of maturity $m$ is rolled over.

The following relations hold between these term premia:

$$
\begin{gathered}
\varphi_{h}\left(t, t^{\prime}, T\right) \equiv \frac{\varphi\left(t, t^{\prime}, T\right)\left(T-t^{\prime}\right)}{t^{\prime}-t}, \\
\varphi_{r}\left(t, t^{\prime}, T\right) \equiv \frac{1}{n} \sum_{j=1}^{n} \varphi(t, t+(j-1) m, t+j m) .
\end{gathered}
$$


Table 1. Forward Term Premium (1-year rates, \%/yr)

$\begin{array}{ccc}\text { Settlement } & \text { Premium } & \text { Std Err } \\ 1 \text { yr } & -0.10 & 0.22 \\ 2 \text { yrs } & -0.24 & 0.36 \\ 3 \text { yrs } & -0.44 & 0.36 \\ 4 \text { yrs } & -0.62 & 0.34\end{array}$

Table 2. Yield spread (over 3-month yields, \%/yr)

$\begin{array}{ccc}\text { Maturity } & \text { Spread } & \text { Std Err } \\ 1 \text { yr } & 0.37 & 0.05 \\ 2 \text { yrs } & 0.49 & 0.10 \\ 3 \text { yrs } & 0.57 & 0.13 \\ 4 \text { yrs } & 0.63 & 0.13 \\ 5 \text { yrs } & 0.68 & 0.13 \\ 10 \text { yrs } & 0.81 & 0.12\end{array}$




\section{References}

[1] Alesina, Alberto, and Lawrence H. Summers (1993), "Central Bank Independence and Macroeconomic Performance: Some Comparative Evidence," Journal of Money, Credit, and Banking 25, 151-162.

[2] Bank of England (1990), "A New Yield Curve Model," Bank of England Quarterly Bulletin, February 1990, 84-85.

[3] Bank of England (1993a), Inflation Report, May 1993.

[4] Bank of England (1993b), Inflation Report, August 1993.

[5] Bank for International Settlements (1993), 69rd Annual Report, Basle.

[6] Batten, Dallas S., Michael P. Blackwell, In-Su Kim, Simon E. Nocera and Yusuru Ozeki (1990), "The Conduct of Monetary Policy in the Major Industrial Countries: Instruments and Operating Procedures," IMF Occasional Paper No. 70.

[7] Bernanke, Ben, and Frederic Mishkin (1992). "Central Bank Behavior and the Strategy of Monetary Policy: Observations from Six Industrialized Countries." NBER Macroeconomics Annual 1992.

[8] Campbell, John Y., and Robert J. Shiller (1991), "Yield Spreads and Interest Rate Movements: A Bird's Eye View," Review of Economic Studies 58, 495-514.

[9] Dahlquist, Magnus, and Lars E. O. Svensson (1993), "Estimation of the Term Structure of Interest Rates with Simple and Complex Functional Forms: Nelson \& Siegel vs. Longstaff \& Schwartz," Working Paper.

[10] Fama, Eugene F., and Robert R. Bliss (1987), "The Information in Long-Maturity Forward Rates," American Economic Review 77, 608-692.

[11] Frachot, Antoine, and Jean-Philippe Lesne (1993), "Expectations Hypotheses and Stochastic Volatilities," Working Paper, Banque de France.

[12] Freedman, Charles (1993), "Formal Targets for Inflation Reduction: The Canadian Experience," Working Paper, Bank of Canada. 
[13] Friedman, Benjamin M. (1990), "Targets and Instruments of Monetary Policy," Chapt. 22 in Friedman, Benjamin M. and Frank H. Hahn (eds), Handbook of Monetary Economics, Volume II, North-Holland, Amsterdam.

[14] Goodfriend, Marvin (1993), "Interest Rate Policy and the Inflation Scare Problem: 1979-1992," in Marvin Goodfriend and David H. Small, eds, Operating Procedures and the Conduct of Monetary Policy. Conference Proceedings, Federal Reserve Board, Washington, D.C.

[15] Hodrick, Robert J., (1987), The Empirical Evidence on the Efficiency of Forwand and Futures Foreign Exchange Markets, Harwood Academic Publishers, London.

[16] Hörngren, Lars, and Hans Lindberg (1993), "The Struggle to Turn the Swedish Krona into a Hard Currency," Working Paper No. 8, Sveriges Riksbank.

[17] Hull, John C. (1993), Options, Futures, and Other Derivate Securities, Second edition, Prentice-Hall, London.

[18] Marston, Richard C. (1993), "Nominal Interest Differentials," manuscript chapter.

[19] Mastronikola, Katerina (1991), "Yield Curves for Gilt-Edged Stocks: A New Model," Bank of England Discussion Paper, Technical Series, No. 49.

[20] McCallum, Bennett T. (1990), “Targets, Indicators and Instruments of Monetary Policy," IMF Working Paper WP/90/41.

[21] McCulloc, J. Huston (1971), "Measuring the Term Structure of Interest Rates," Journal of Business 44, 19-31.

[22] McCulloch, J. Huston (1975), "An Estimate of the Liquidity Premium," Journal of Political Economy 83, 62-63.

[23] McCulloch, J. Huston (1990), "US Term Structure Data, 1946-1987," Appendix B in Shiller (1990).

[24] Nelson Charles R., and Andrew F. Siegel (1987), "Parsimonious Modeling of Yield Curves," Journal of Business 60, 473-489.

[25] Rogoff, Kenneth (1985), "The Optimal Degreee of Commitment to an Intermediate Monetary Target," Quarterly Journal of Economics 100, 1169-1189. 
[26] Rose and Svensson (1993), "Expected and Predicted Realignments: The FF/DM Exchange Rate during the EMS, 1979-1993," Working Paper.

[27] Shiller, Robert J. (1990), "The Term Structure of Interest Rates," Chapt. 13 in Friedman, Ben M., and Frank H. Hahn (eds), Handbook of Monetary Economics, Volume I, North-Holland, Amsterdam.

[28] Svensson, Lars E.O. (1992), "Targets and Indicators with a Flexible Exchange Rate," Monetary Policy with a Floating Exchange Rate, Sveriges Riksbank, December 1992, 15-24.

[29] Svensson, Lars E.O. (1993a), "The Forward Interest Rate Curve - An Indicator of Market Expectations of Future Interest Rates, Inflation and Exchange Rates ${ }^{n}$ (in Swedish), Ekonomisk Debatt 21-3, 219-234.

[30] Svensson, Lars E.O. (1993b), "Term, Inflation and Foreign Exchange Risk Premia: A Unified Treatment," Seminar Paper No. 548, Institute for International Economic Studies.

[31] Svensson, Lars E.O. (1994), "Fixed Exchange Rates as a Means to Price Stability: What Have We Learned?" European Economic Review, forthcoming.

[32] Sveriges Riksbank (1993), Monetary Policy Indicators, June 1993.

[33] Woodward, G. Thomas (1990), "The Real Thing: A Dynamic Profile of the Term Structure of Real Interest Rates and Inflation Expectations in the United Kingdom, 1982-89, ${ }^{n}$ Journal of Business 63, 373-398. 


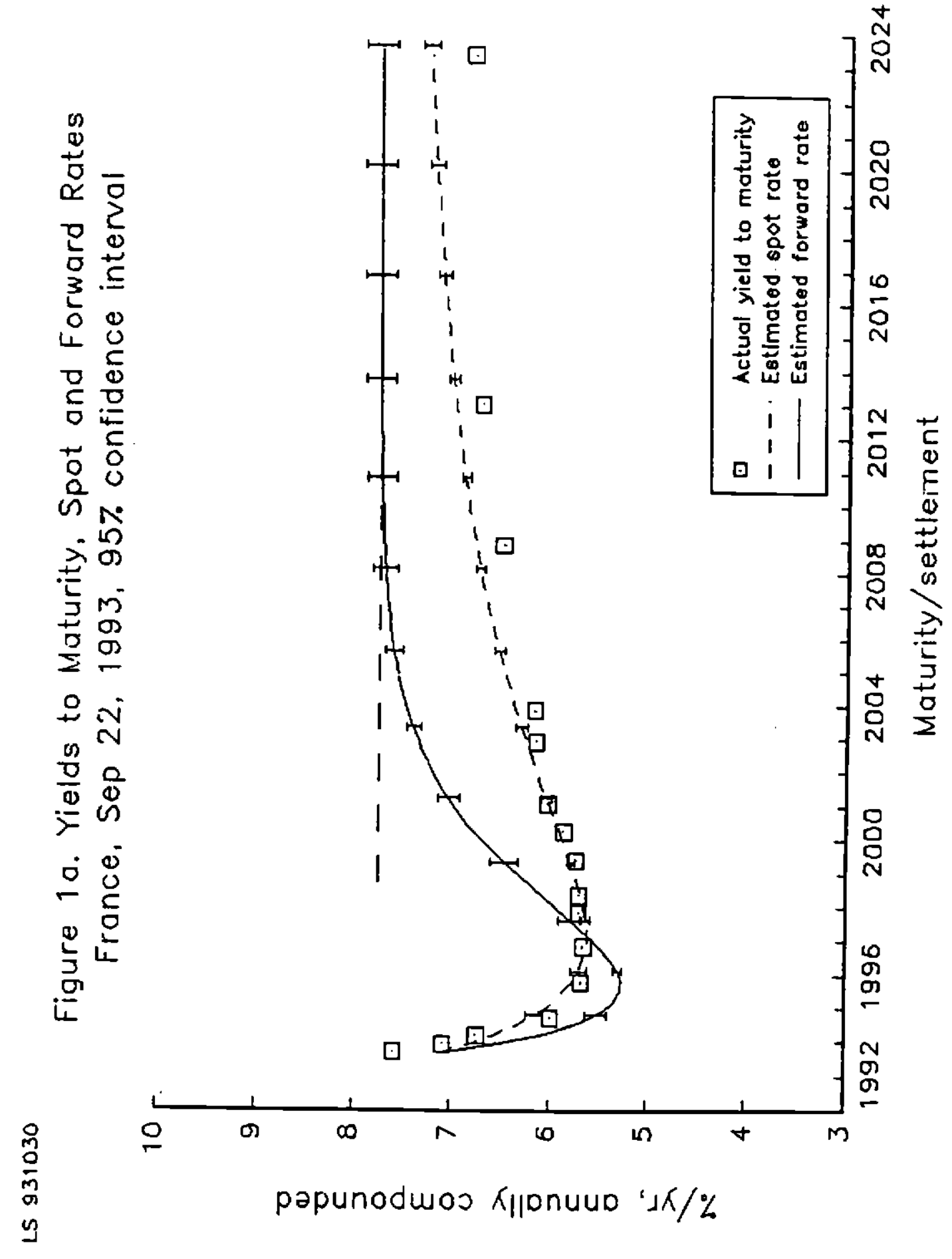




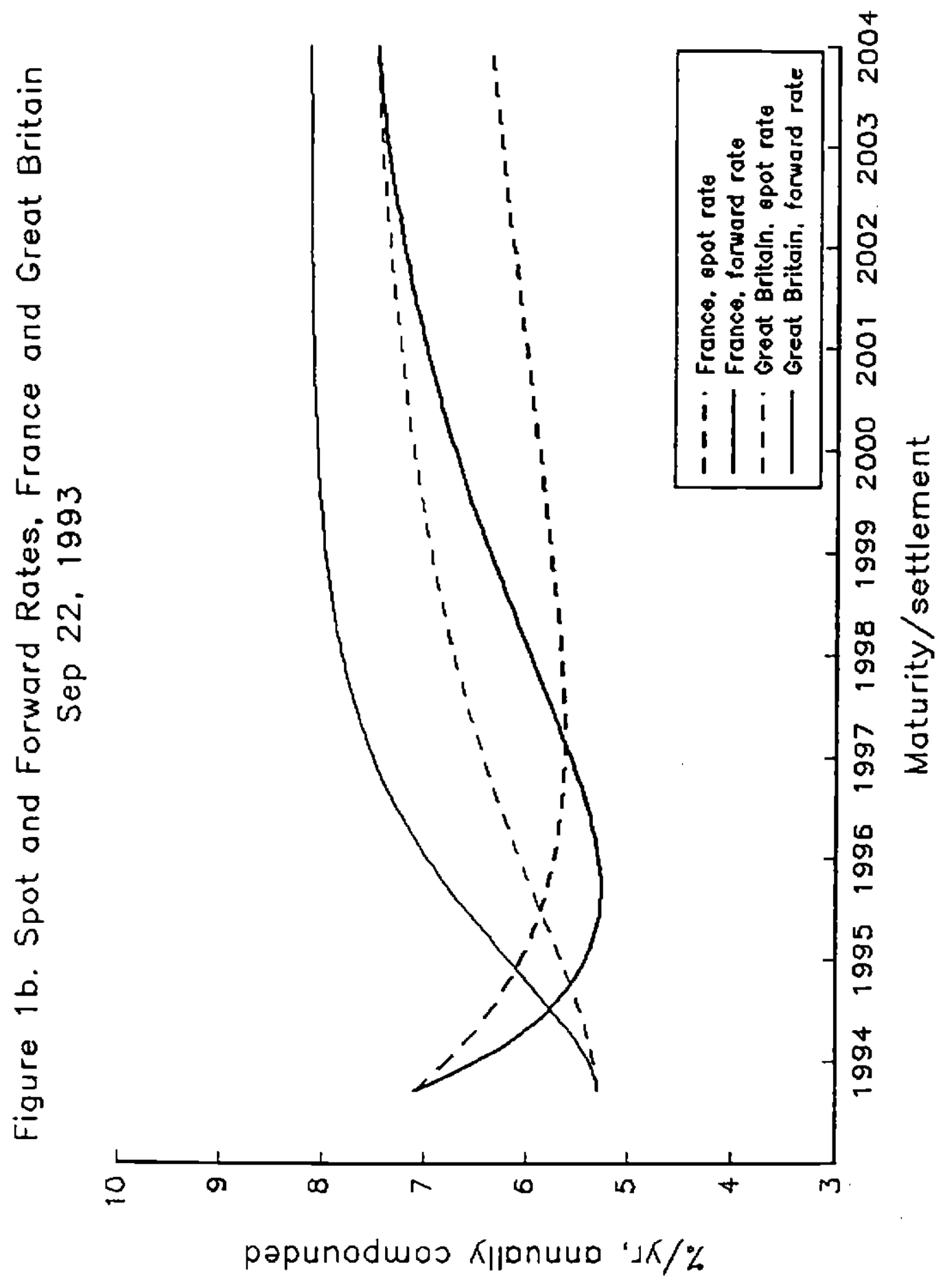




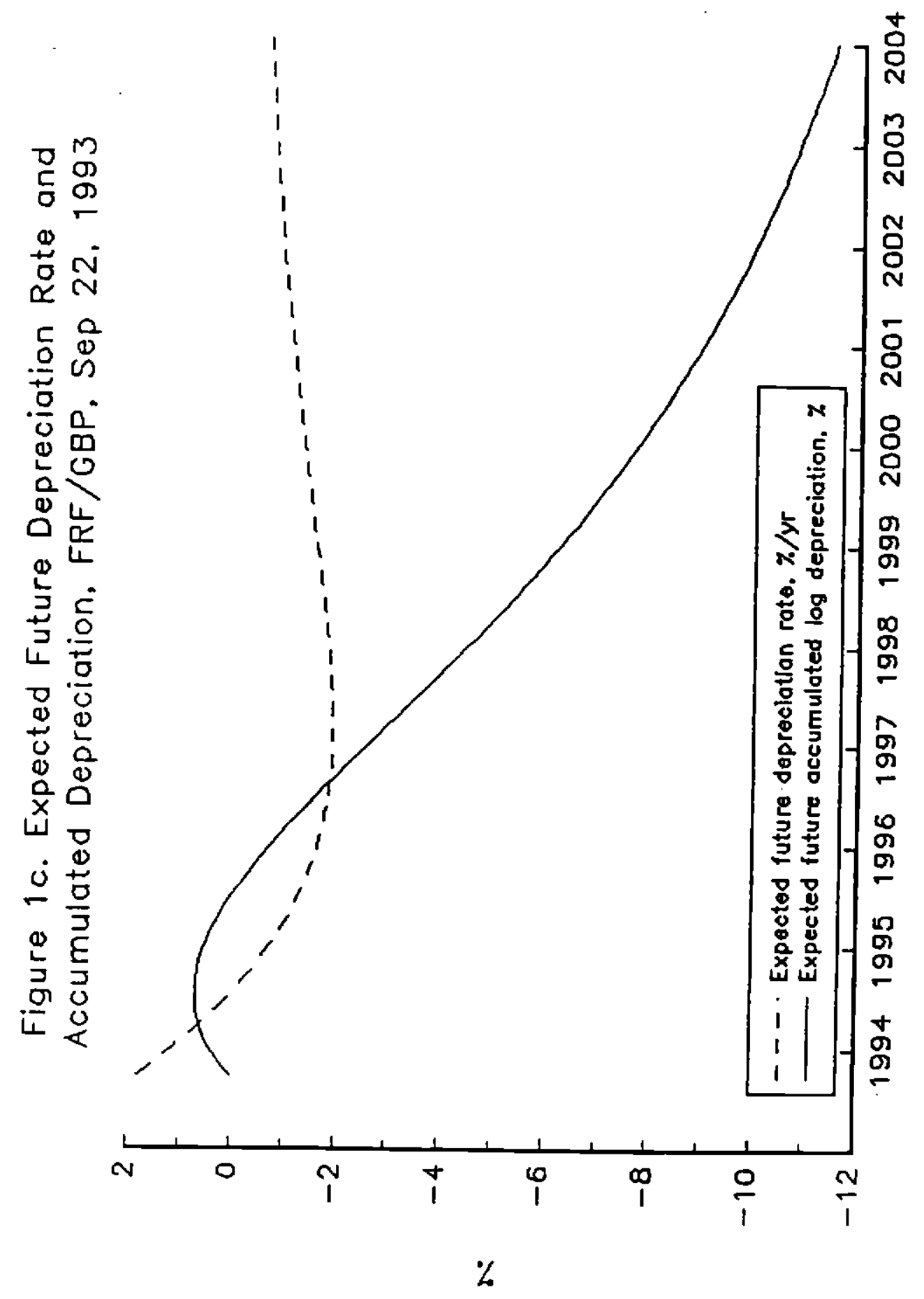



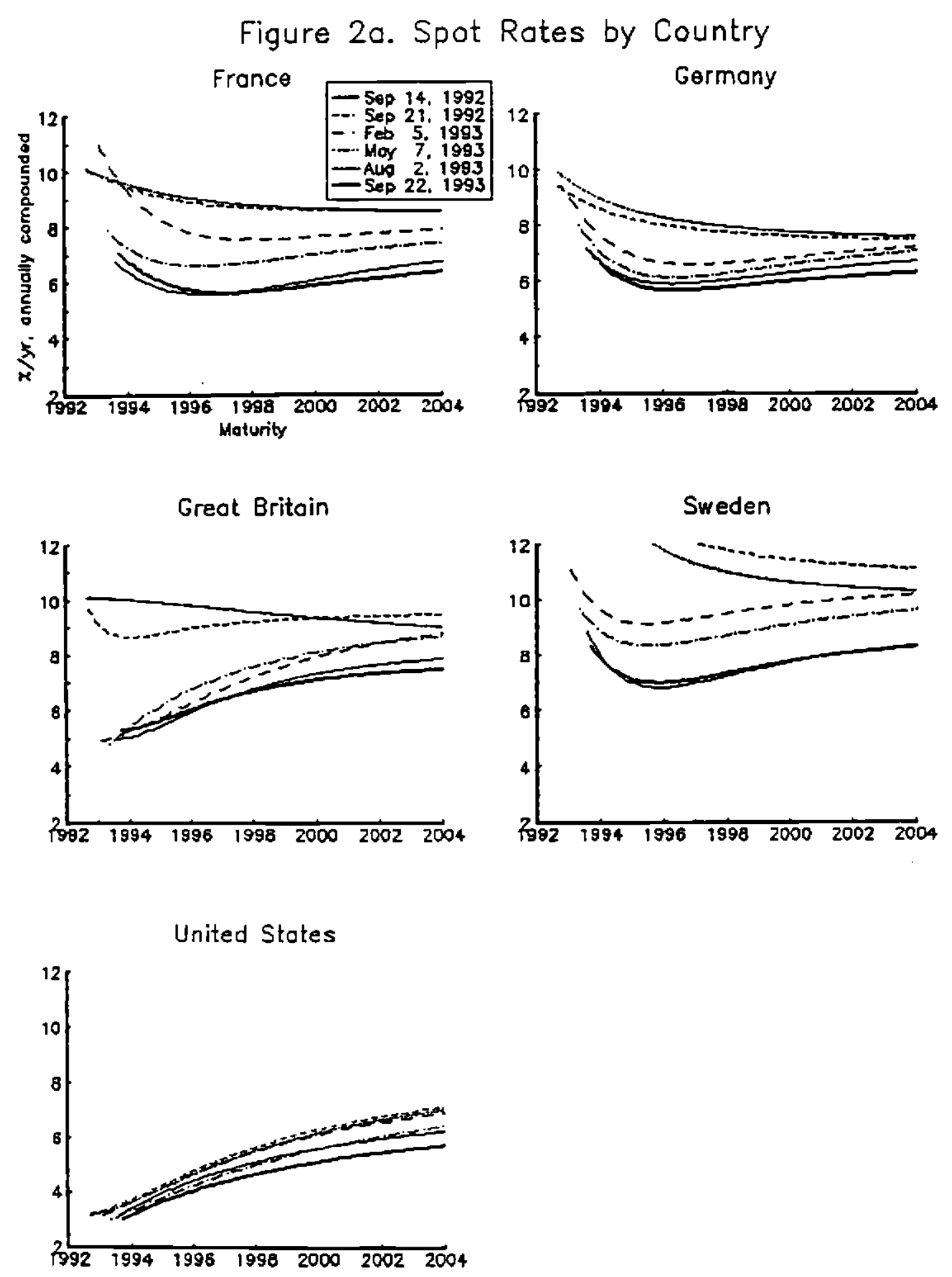
Figure 2b. Spot Rates by Trade Date

Sep 14, 1992

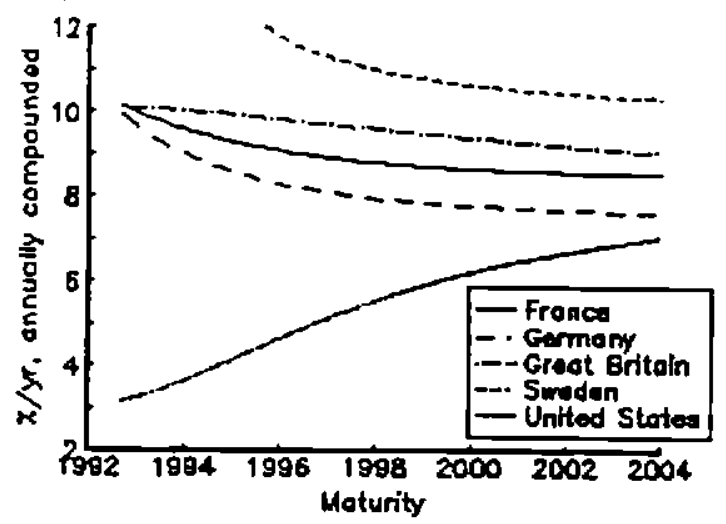

Feb 5, 1993

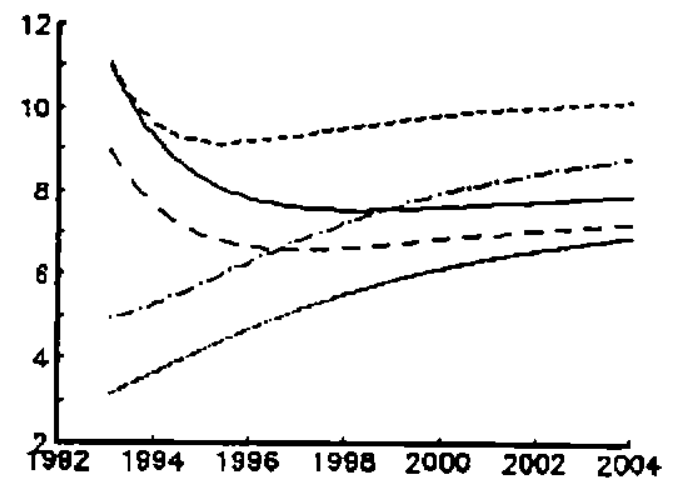

Aug 2, 1993

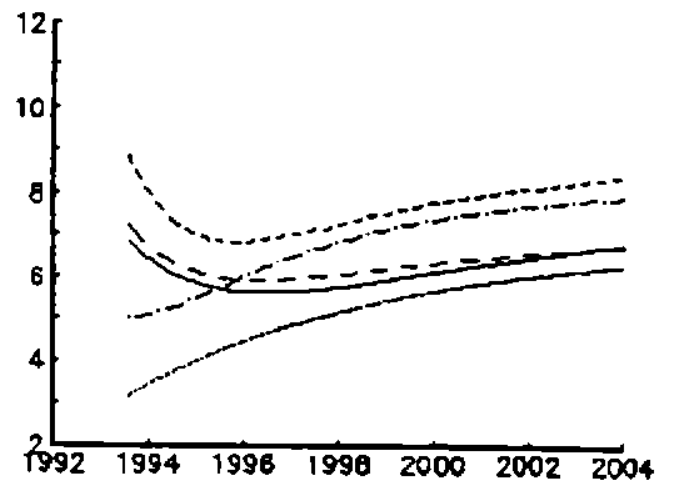

Sep 21, 1992

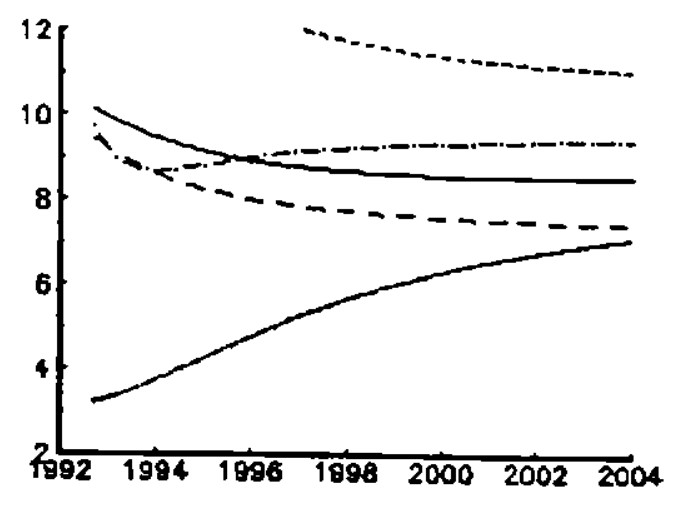

May 7, 1993

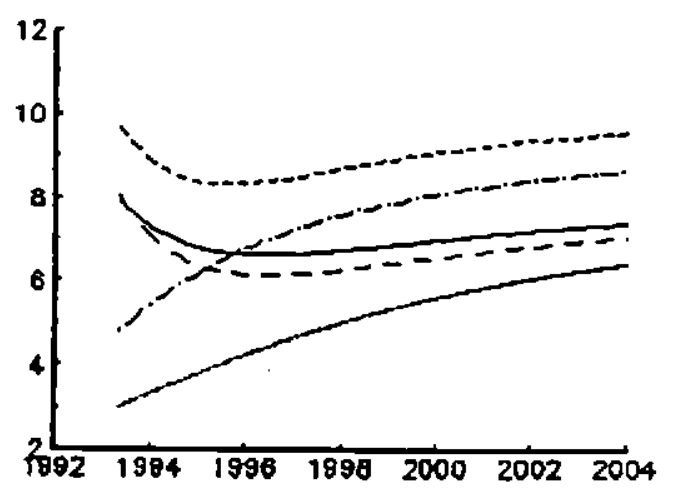

Sep 22, 1993

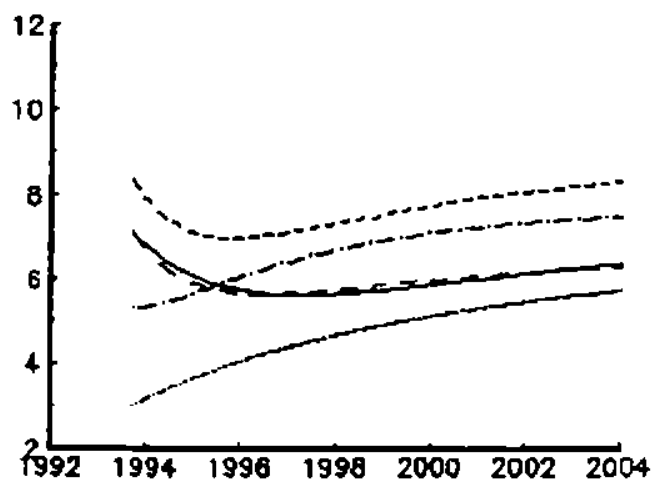


Figure 30. Forward Rates by Country France Germony
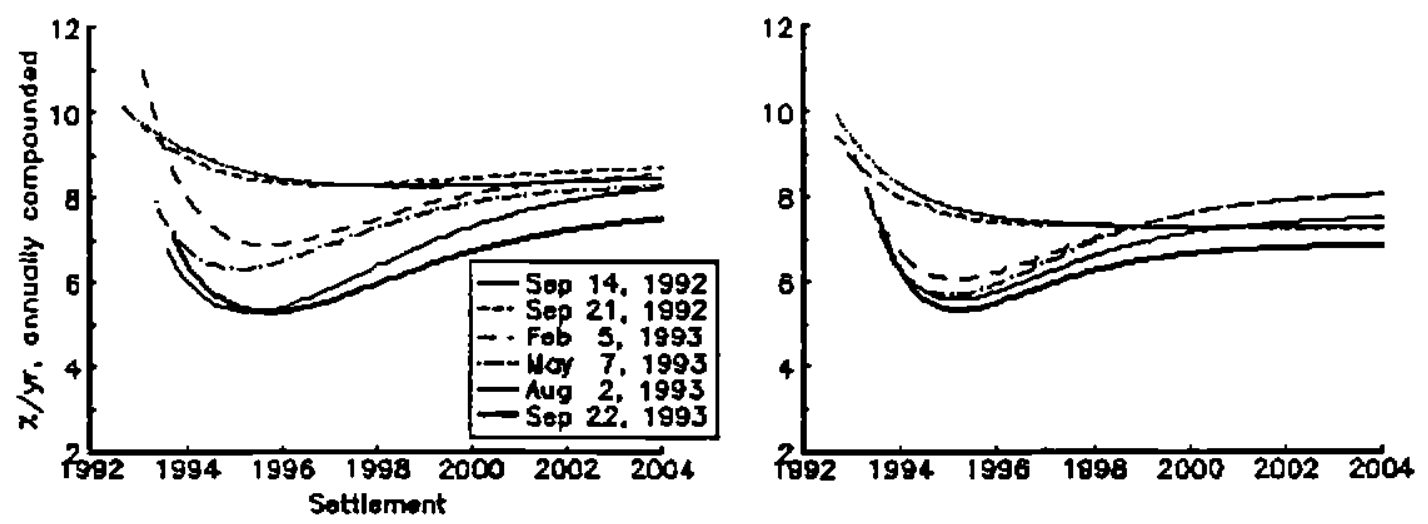

Great Britain

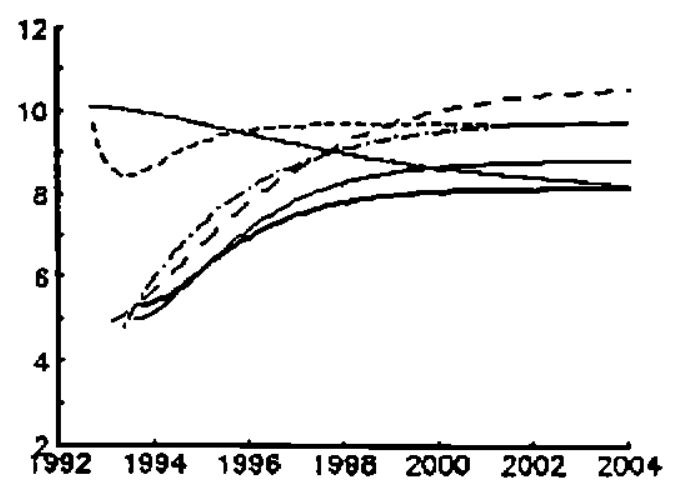

Sweden

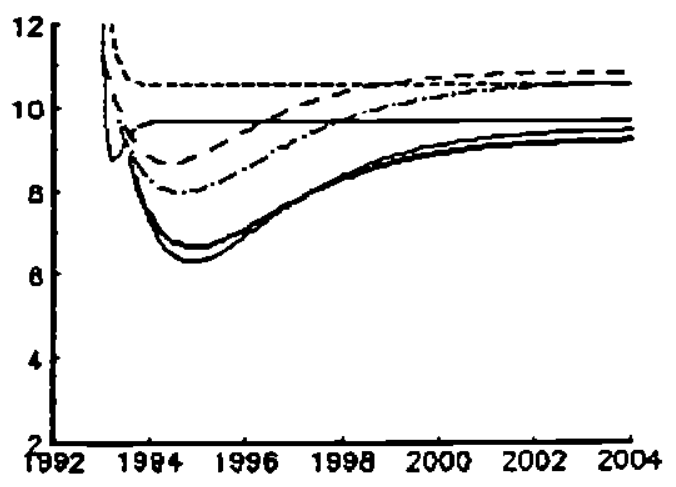

United Stotes

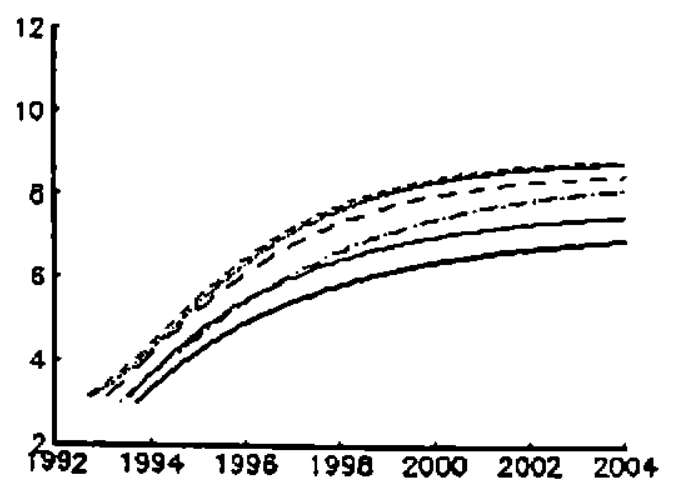


Figure 3b. Forward Rates by Trade Date

Sep 14, 1992

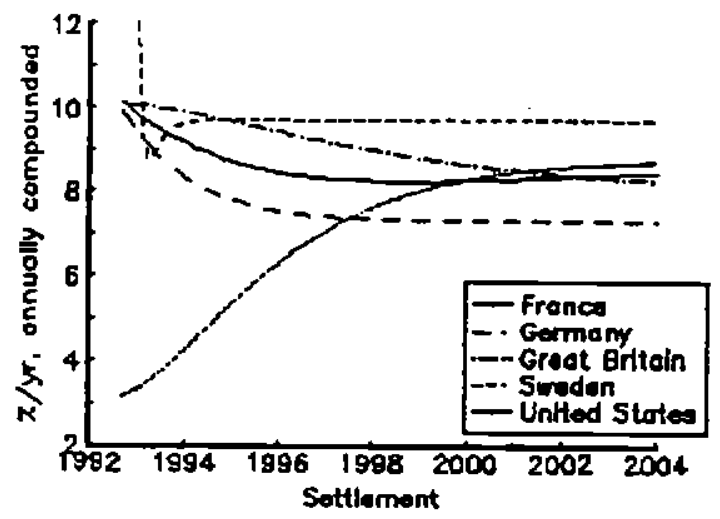

Feb 5, 1993

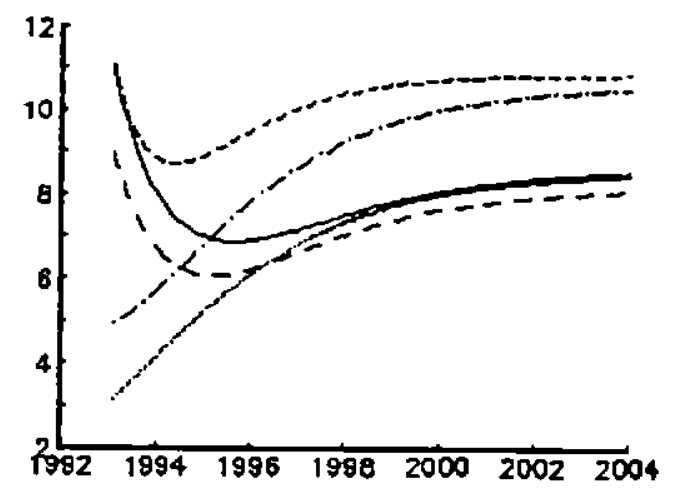

Aug 2, 1993

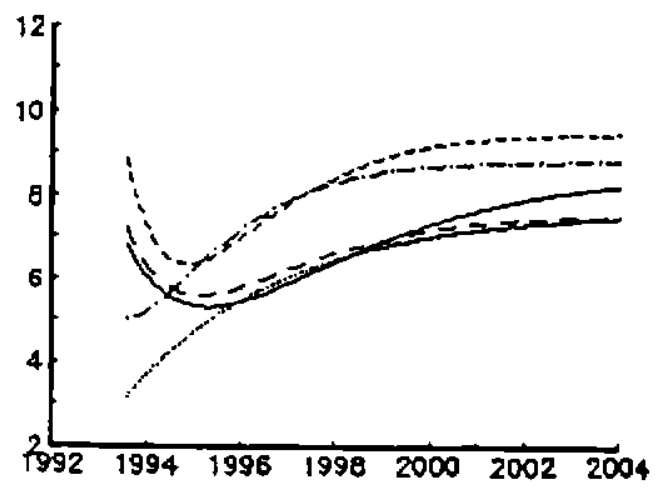

Sep 21, 1992

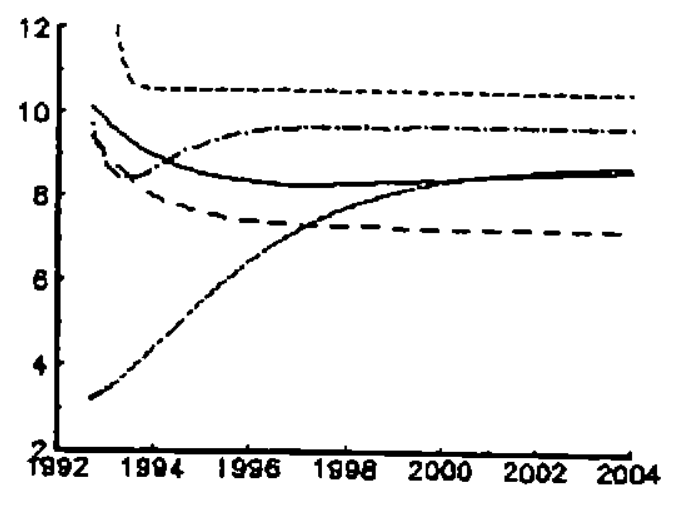

May 7, 1993

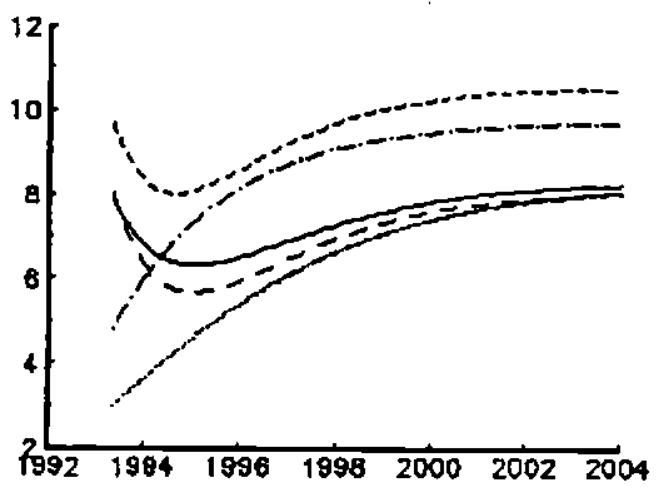

Sep 22, 1993

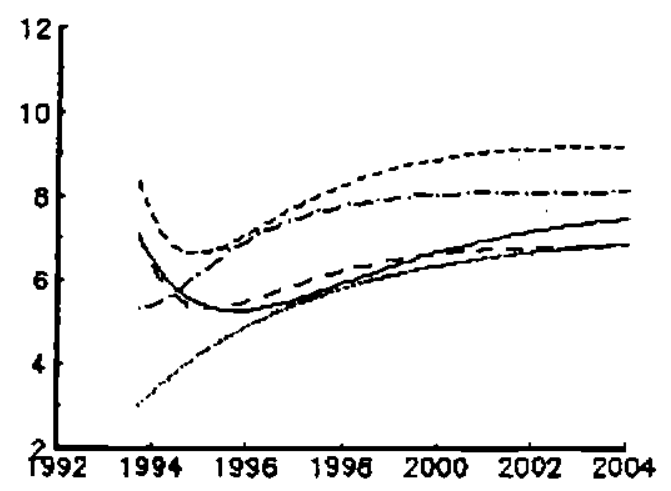


Figure 40. Expected Future Exchange Rates by Currency

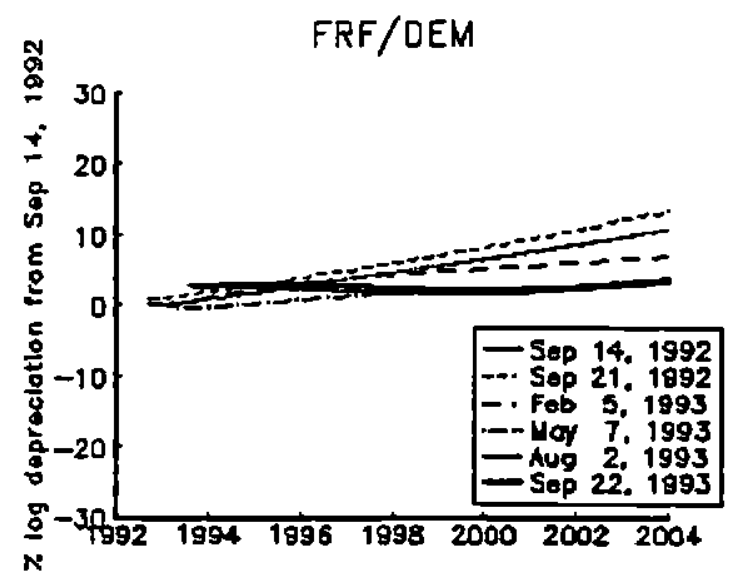
GBP/DEM

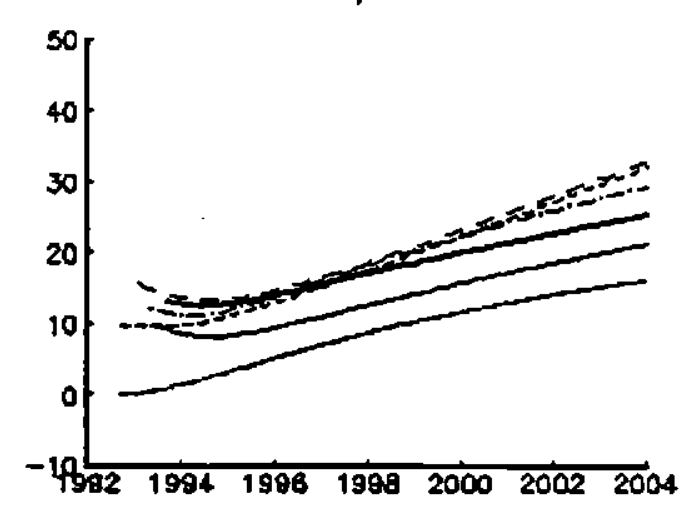

SEK/DEM

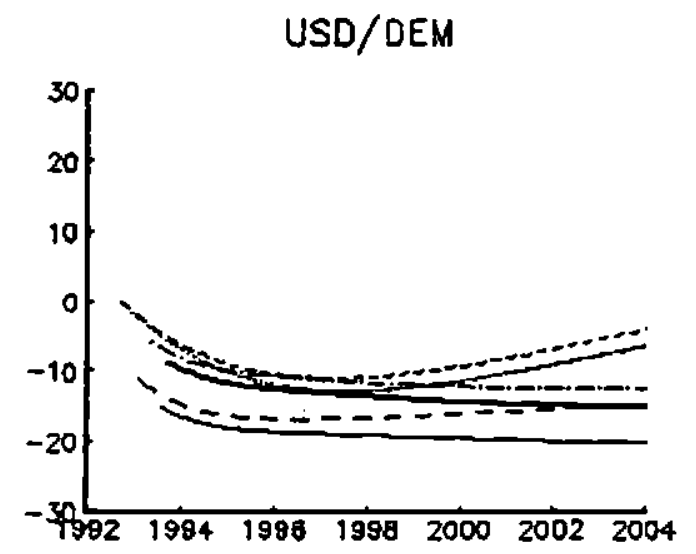


Figure 4b. Expected Future Exchange Rates by Trade Date

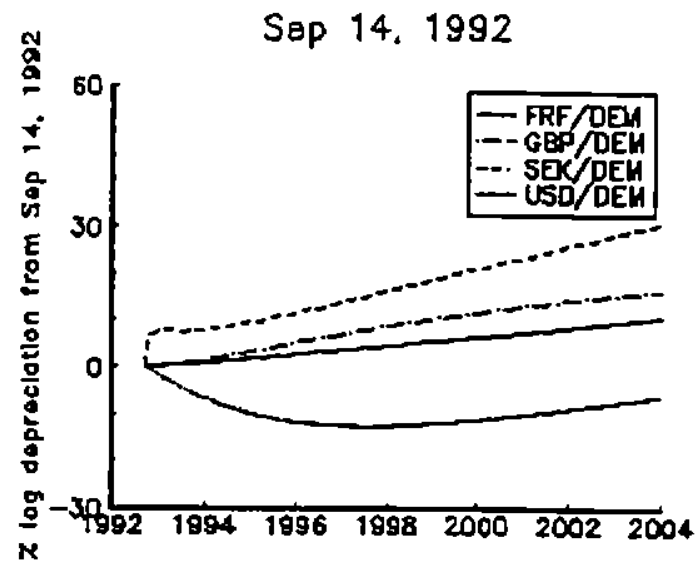

Sep 21, 1992

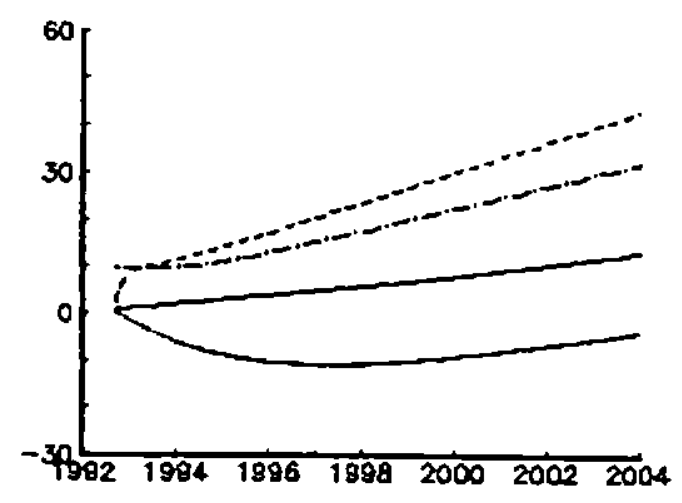

Feb 5, 1993

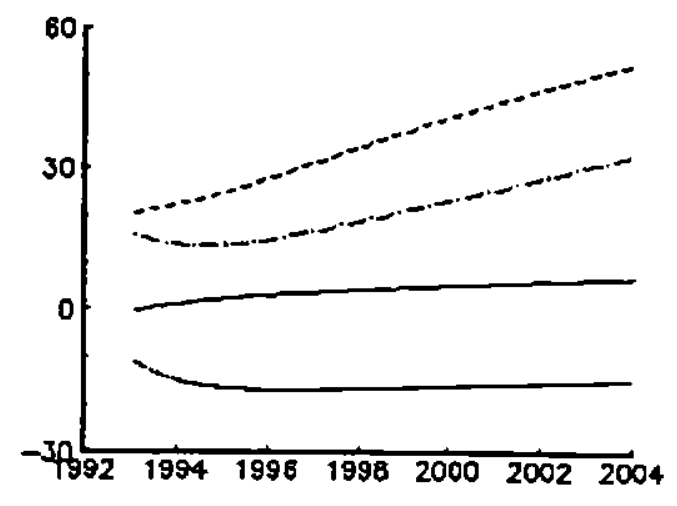

May 7. 1993

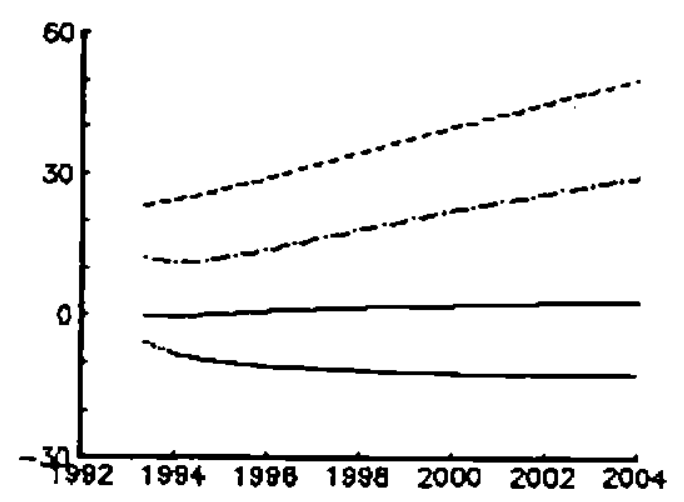

Aug 2, 1993

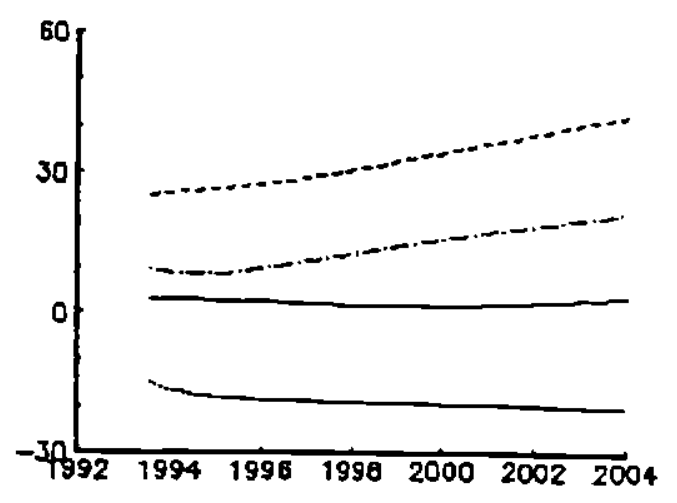

Sep 22, 1993

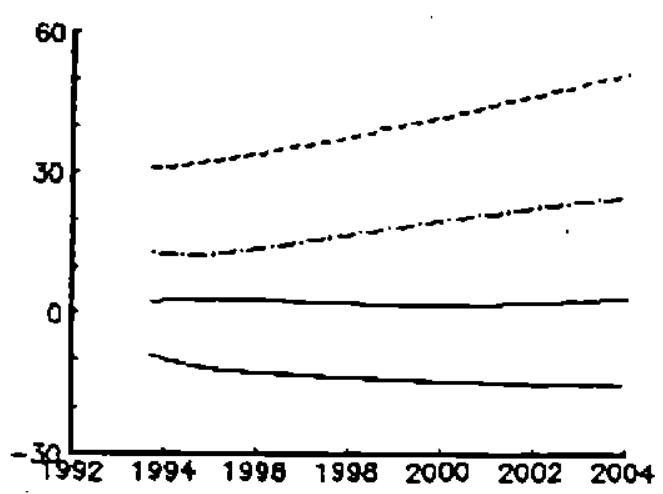




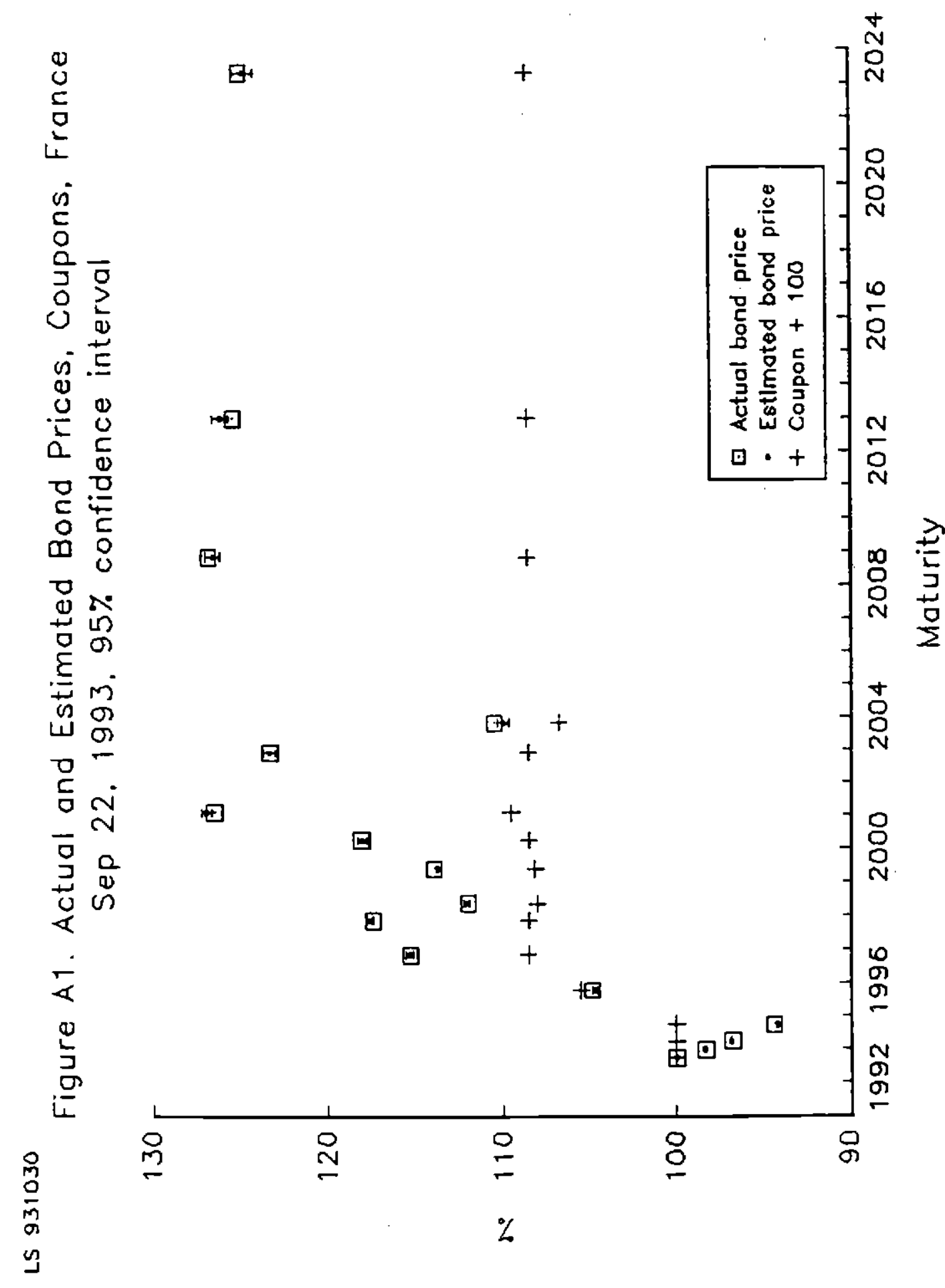

